\title{
Iniciativas COIL de Diseño Gráfico en tiempos de Pandemia: aprendizaje basado en proyectos culturales
}

\author{
COIL Graphic Design Initiatives in times of Pandemic: benefits and limitations
}

\section{MARIANA SORAYA LOZADA MONDRAGÓN}

Pontificia Universidad Católica del Ecuador (PUCE), Quito, Ecuador.

\section{Resumen}

Este proyecto es una iniciativa COIL que parte desde la Pontificia Universidad Javeriana (PUJ) de Cali, Colombia y que esta vez se trabaja junto a la Pontificia Universidad Católica del Ecuador (PUCE). Destinado a los estudiantes de primer nivel de las carreras de Diseño Gráfico y ejecutada en cinco semanas en modalidad presencial con asistencia remota.

Es una experiencia pedagógica que parte de un proceso de observación guiada atravesada por lo experiencial y sensorial, que busca redescubrir la identidad a través de la mirada de elementos visuales urbanos así como de las dinámicas urbanas propias de la cultura y la sociedad de los lugares observados: el Centro Histórico del Distrito Metropolitano de Quito y el de Cali, para posteriormente reinterpretar sus códigos, conectar las dos culturas y proponer nuevos discursos visuales compartidos y cruzados, dando como resultado la agenda calendario 2021 denominada "Miradas escondidas del Centro Histórico de Quito y Cali".

Artículo original Original Article

Correspondencia/ Correspondence Mariana Soraya Lozada Mlozada685@puce.edu.ec

Financiación/Fundings Sin financiación

Received: 23.03.2021 Accepted: 25.11 .2021

PALABRAS CLAVE: Diseño, investigación, cultura, metodología, internacional.

CÓMO CITAR ESTE TRABAJO / HOW TO CITE THIS PAPER

Lozada M. S. (2021). Iniciativas COIL de Diseño Gráfico en tiempos de Pandemia: aprendizaje basado en proyectos culturales. Umática. Revista sobre Creación y Análisis de la Imagen, 4.

https://doi.org/10.24310/Umatica.2021.v3i4.12241

Umática. 2021; 4. https://doi.org/10.24310/Umatica.2021.v3i4.12241 


\title{
COIL Graphic Design Initiatives in times of Pandemic: benefits and limitations
}

\section{MARIANA SORAYA LOZADA MONDRAgón}

Pontificia Universidad Católica del Ecuador (PUCE), Quito, Ecuador.

\begin{abstract}
This project is a COIL initiative that starts from the Pontificia Universidad Javeriana (PUJ) of Cali, Colombia and that this time is working with the Pontifical Catholic University of Ecuador (PUCE). Aimed at first-level students of Graphic Design careers and executed in five weeks in face-to-face mode with remote assistance.

It is a pedagogical experience that starts from a process of guided observation crossed by the experiential and sensorial. Which seeks to rediscover identity through the look of urban visual elements as well as the urban dynamics of the culture and society of the places observed: Historical Center of Distrito Metropolitano de Quito and that of Cali. To reinterpret after their codes. Connect the two cultures and propose new shared and crossed visual discourses. Resulting in the 2021 calendar agenda called "Hidden views of the Historic Center of Quito and Cali".
\end{abstract}

KEY WORDS: Design, research, culture, methodology, international.

Summary - Sumario

Antecedentes

Contextualización

Base teórico - conceptual

Producción

Objetivos y metodología

Fase 1: Conociendo al otro

Fase 2: Formulando preguntas

Fase 3: Explorando ideas

Fase 4: Apropiando el conocimiento

Resultados

Lecciones aprendidas

Oportunidades de mejora

Conclusiones 


\section{Antecedentes}

En 2018, se realiza un encuentro entre varias universidades Jesuitas y se crea la Red de Diseño AUSJAL ${ }^{1}$ con el fin de juntar esfuerzos y empezar la ejecución de proyectos de co-creación, a partir del cual surge una iniciativa de la PUJ de Cali, denominada "Identidades comunes, identidades cruzadas", la que se pone en marcha por primera vez en 2019 junto a la Universidad Iberoamericana de México; y, por segunda ocasión en 2020 con la Carrera de Diseño Gráfico de la Pontificia Universidad Católica del Ecuador (PUCE).

En esta segunda versión del proyecto que se ejecuta con la PUCE, participan estudiantes de primer nivel de las Carreras de Diseño Gráfico de ambas univeersidades, 33 estudiantes de la PUJ de Cali, Colombia y 24 estudiantes de la Pontificia Universidad Católica del Ecuador (PUCE), de las materias Diseño Bidimensional y Fundamentos del Diseño Gráfico respectivamente.

Al desarrollarse esta segunda edición de "Identidades comunes, identidades cruzadas", justamente a inicios del el primer trimestre del año 2020, época en que el mundo enfrentaba la pandemia COVID-19, tanto Quito como Cali se mantenían con restricciones de movilidad, lo que representó un gran desafío, pues el proyecto fue pensado originalmente para la presencialidad, pero en esta ocasión tuvo que adaptarse a la modalidad de clases mediante asistencia remota, ya que debido a temas de bioseguridad, tanto la Pontificia Universidad Católica del Ecuador como la Pontificia Universidad Javeriana de Cali empezaron a trabajar de esa manera.

Como premisa, se analiza la posibilidad de lograr que los estudiantes descubran su contexto urbano mediante recorridos físicos o virtuales de los espacios históricos de la ciudad a la que pertenecen así como la de sus pares internacionales, con el fin de fortalecer su memoria visual y recopilar información que les permita comprender mejor tanto su contexto como el de sus pares universitarios, estableciéndose como una oportunidad para conocer también otros lugares y culturas, así como para aplicar un proceso metodológico de investigación en el diseño que les permita comprender la importancia de esta fase.

\section{Contextualización}

El contexto académico en el cual se desarrolló el proyecto fue mediante el sistema Collaborative Online International Learning o de Aprendizaje Internacional Colaborativo en Línea (COIL)², que en el caso de la PUCE se promovió con gran fuerza a través de las uni-

1. Red de escuelas de diseño de la Asociación de Universidades Confiadas a la Compañía de Jesús en América Latina conformada para realizar trabajos de colaboración académica que fortalezcan la experiencia de enseñanza del Diseño.

2. Es una estrategia de aprendizaje colaborativo que busca conectar a profesores y estudiantes de diferentes culturas o nacionalidades con el fin de extender sus experiencias académicas, brindarle a los estudiantes nue- 
versidades con las que posee convenios o alianzas estratégicas, y que desde la Facultad de Arquitectura Diseño y Artes se logró el vínculo con la PUJ de Cali para trabajar en las materias eje de primer semestre, antes mencionadas, para promover la investigación en proyectos de diseño, vincular a los estudiantes con el público objetivo y comprender los resultados de dicha investigación para tomar decisiones en el diseño de una agenda calendario 2021 denominada "Miradas escondidas del Centro Histórico de Quito y Cali", que refleje visualmente la riqueza cultural que comparten ambas ciudades.

Con esta propuesta se buscó el vínculo de los estudiantes a contextos reales de investigación en el Diseño, promoviendo además la democratización de la internacionalización sin necesidad de la movilidad propia, lo que abre nuevas puertas a estudiantes que en circunstancias normales quizá no tendrían la oportunidad de trasladarse físicamente a otro país y mucho menos permanecer por cinco semanas en esos lugares para realizar proyectos de características similares a este. En este punto la tecnología jugó un papel fundamental, puesto que las herramientas virtuales permitieron romper las fronteras físicas, así como culturales y favorecieron la optimización de las tareas, además de facilitar el contacto académico entre docentes y estudiantes.

Además, con el fin de reducir el área de estudio y pensando en la posibilidad que tenían los estudiantes en aquel momento para vincularse con otras personas, se delimitó a los centros históricos de ambas ciudades, específicamente a los espacios donde existía una fuerte presencia de los negocios tradicionales de bajo costo, pues representan una importante herencia patrimonial tangible e intangible de estas urbes y a pesar de ello, varios se encuentran en riesgo de desaparecer a causa de diversas razones, entre estos negocios se encuentran: las ventas de comidas calientes, comidas frías, bebidas, dulces, indumentaria, juguetes tradicionales, artesanías, artículos religiosos, instrumentos musicales, artistas callejeros, negocios tradicionales de la calle y negocios tradicionales de claustro.

\section{Base teórico - conceptual}

El proyecto se enfocó en dar lugar a una experiencia pedagógica de observación en la cual se vincule por primera vez al estudiante de las Carrera Diseño Gráfico de ambas universidades con su público objetivo y su contexto, así como las prácticas sociales y culturales propias de cada lugar; que les permita relacionar sus primeros conocimientos de diseño gráfico con la realidad que los circunda, les permita aplicar esos conocimientos a procesos reales y de lugar a reflexiones posteriores teniendo en consideración lo que menciona Bransford, J., Et. Al. (2000) cuando se refiere a que es necesario "intentar descubrir lo que piensan los estudiantes en relación con los problemas a abordar, debatir con sensibilidad sobre los conceptos erróneos y brindarles la posibilidad de que sigan pensando en situaciones

vas posibilidades de trabajo en equipo y darles la oportunidad de vivir experiencia interculturales significativas o mejorarlas. En este proceso se busca que las asignaturas de las universidades participantes se integren en una actividad mínima de 4 semanas para realizar un proyecto definido.

Umática. 2021; 4. https://doi.org/10.24310/Umatica.2021.v3i4.12241 
que les permitan reajustar sus ideas", y vincularse a los procesos investigativos, pues como menciona Múnera, M., Londoño, C.

"La investigación en diseño es una práctica similar, ya que "saber investigar" para ese tan anhelado "saber que hacer"; requiere de diseñadores que estén dispuestos a vivir la investigación como experiencia, pensadores inquietos y observadores que experimentan, crean y re-crean; la investigación social en diseño es una opción que propone indagar y cuestionar la vivencia de la práctica del diseño." ... "El diseño debe materializar, sí, pero el diseñador debe investigar, indagar y encontrar respuestas a realidades concretas mediante actos creativos, sin desconocer hechos sociales. Se trata de comprender entonces, que es en esta dimensión donde los diseñadores como actores sociales, con sus prácticas investigativas en ese saber-hacer pueden materializar sus ideas y momentos creativos en forma de conceptos, productos y/o servicios, sistemas de productos y/o servicios." (p. 170)

Esto se complementa con lo que indica Yedaide (2016) al mencionar que "La conciencia de los retos de la creación - condición indispensable del diseño - genera una preocupación por el salto profético que el estudiante debe dar al asumir una momentánea pero rotunda suspensión de las certezas cuando se dispone a abocarse a la tarea de aprender lo que no puede ser siquiera imaginado o previsto de antemano" (p. 2) pues con ello se generan procesos mucho más críticos y enriquecedores para los estudiantes. En este punto es importante mencionar a Roberto Doberti, quien asegura que las prácticas sociales no son unívocas, sino que se pueden presentar de diferentes maneras, por lo que es fundamental que el diseñador las vaya conociendo en su entorno real, y que por otro lado coteje la información con lo que otros ya han descubierto y escrito.

Es por ello que se vincula la propuesta al diseño social, considerando además lo que menciona Margolín (2012) "la intención principal del diseño social es la satisfacción de las necesidades humanas" (p. 64) pero acota que esto no impide que el diseño social se vincule con el diseño para el mercado y propone un enfoque multifacético para responder a una serie de preguntas que buscan generar espacios de observación, reflexión multidisciplinar, una investigación centrada en el desarrollo y la evaluación de productos socialmente responsables.

Y complementando con lo que acota Julier (2010) Hablando sobre el consumo del diseño "al pensar en términos de consumo como "práctica", podemos comenzar a explorar una concepción alternativa que tenga en cuenta las peculiaridades de sus diversos modelos y localizaciones, la posible interconexión entre los objetos, espacios e imágenes y las reglas que la regulan." E indica que una consideración de la práctica conjuga tanto procesos materiales como inmateriales, incidiendo en la capacidad de relación entre las personas y los artículos, mostrando características propias del entorno, pero al mismo tiempo hallándose en constante evolución. 
En el caso específico del proyecto y su vinculación a las dinámicas de venta de productos tradicionales de bajo costo de ambas ciudades, el Distrito Metropolitano de Quito (DMQ) y la ciudad de Cali, se consideró la exploración en estos espacios, pues es una manera sencilla de acercar al estudiante al análisis del contexto, pues es algo propio de su día a día y fácil de analizar a pesar de no poder acercarse físicamente a los lugares establecidos para cada grupo, además fue también un buen pretexto para conectarlos con acciones de Diseño Social, pues el servicio al otro es uno de los valores de las Universidades Jesuitas, además que como menciona María Ledesma, este tipo de diseño permite el planteamiento de intervenciones con continuidad temporaria, preocupándose siempre por como el diseño incide en la cadena de valor de producción, en el desarrollo de identidades territoriales y en los procesos de gestión social, económica y cultural (2017).

Por otra parte, también es importante tomar en cuenta lo que indica la World Design Organization (WDO) respecto a la postura del Diseño como una disciplina de servicio a diversos sectores sociales desde perspectivas económicas, culturales y sociales que han reinventado las ciudades y mejorado la calidad de vida sustentados en los Objetivos de desarrollo sostenible de las Naciones Unidas y que promueve varias actividades sociales, entre ellas las relacionadas con el aporte del diseño a las pequeñas comunidades.

Es así como, para este proyecto los estudiantes necesitaron vincularse a la realidad misma de los negocios de bajo costo, conocerlos, comprenderlos, explorarlos y buscar esos aspectos que les permitirían presentar su realidad y visibilizarlos a través del calendario.

En este punto fue trascendental también que los estudiantes reconocieran las prácticas propias de su cultura, estableciendo similitudes y diferencias con otros grupos, haciendo una crítica lógica a estas prácticas y logrando identificar aquellos aspectos que les permitan representar visualmente a estos lugares a través de sus respectivas temáticas y emitir un mensaje unívoco, pues como señala Arfuch en la memoria del XII seminario para docentes de arte Cultura e Imagen (S.f.):

"Aquí se juega la importancia de la apropiación visual como experiencia educativa, lo que puede lograrse con el trabajo sobre la mirada, y sus recorridos siempre impredecibles, unido a lo que el arte en particular puede aportar al universo de cada persona más allá de la fascinación o la identificación afectiva ante una obra: la ampliación de la imagen del mundo, el conocer y comprender, el afinamiento de la sensibilidad y la destreza de la percepción, la agudeza analítica y crítica, para no quedar inmunes a la sorpresa o a la conmoción, pero sin cercenar la libertad de la mirada." (p.15)

Es así como no basta con la investigación antes mencionada, sino que fue necesario también esa apropiación visual para que pudiesen seleccionar los insumos correctos para la transmisión de un mensaje efectivo. 
Y por otra parte fue ineludible también vincular todos los aspectos mencionados con la fundamentación, pues según lo que señala Doberti en el mismo documento mencionado unos párrafos antes:

"Las justificaciones pueden anidar en distintos ámbitos: derivarse de conocimientos reputados como científicos, originarse en criterios estéticos, en apelaciones al sentido común imperante, tener bases religiosas o tal vez míticas. Para distintas culturas y para distintas prácticas, las justificaciones resultarán más eficaces o convincentes según que sus principios se apoyen en uno $u$ otro lugar." (S.f)

Esto es muy evidente en la ejecución del proyecto, pues los estudiantes lograron fundamentar sus propuestas por una parte mediante los respaldos teóricos de definen las decisiones de diseño, pero en gran parte también por los datos obtenidos a través de la investigación de campo y las experiencias propias de cada grupo de estudiantes con el entorno analizado.

\section{Producción}

\section{Objetivos y metodología}

Para este proyecto se planteó como objetivo desarrollar un calendario intercultural que, a través de una propuesta gráfica, refleje los aspectos culturales y sociales más relevantes de los Centros Históricos del DMQ y Cali.

Los objetivos específicos del proyecto se vincularon a:

- Generar espacios de investigación que, mediante el intercambio de información teórica y empírica, permita que los estudiantes construyan una nueva visión de identidad de las ciudades en las que viven.

- Visibilizar a través de recursos gráficos, el resultado del trabajo realizado y los conocimientos adquiridos entre los estudiantes de ambas Universidades.

- Analizar mediante testeos base la calidad técnica y conceptual del producto para que se considere listo para la producción masiva.

Para este proyecto se trabajó con el método de Colores por la vida ${ }^{3}$, una propuesta de aprendizaje de servicio que se centra en generar proyectos de diseño a través de una mirada crítica del entorno y reconociendo a profesores y estudiantes como agentes de cambio en

3. Proyecto creado por docentes de la Universidad Javeriana de Cali con el fin de privilegiar los procesos de enseñanza ligados a aspectos, disciplinares, interdisciplinares, con una mirada crítica del entorno, siendo profesores y estudiantes agentes de cambio en su contexto, dejando en pausa a la tradicional clase magistral para insertarse en un proceso proyectual mucho más cercano a las personas y sus realidades, de tal manera que el estudiante, desde el entorno universitario pueda tener ya un acercamiento a lo que será su desempeño profesional.

Umática. 2021; 4. https://doi.org/10.24310/Umatica.2021.v3i4.12241 
sus contextos" (Arboleda, 2018, p.121) además de "promover actividades de enseñanza, en el marco de procesos de resolución de problemas, que permitan a los estudiantes aplicar los conocimientos en situaciones similares a las que solucionarían, una vez sean profesionales" ídem, obviamente este proceso toma como base la modalidad del aprendizaje basado en proyectos, donde se prioriza el aprendizaje desde la participación en la solución de problemáticas reales y de impacto significativo, solo que en este caso, debido al nivel de los estudiantes se partió de una propuesta más sencilla.

En el caso específico de los estudiantes de primer nivel que participaron en el proyecto, esto fue fundamental, pues les abrió el panorama de la idea inicial con la que ingresaron a la Carrera y les permitió comprender la importancia de sus funciones como futuros profesionales y su responsabilidad frente a las necesidades identificadas en entornos tan propios y cercanos que, sin este tipo de acercamientos, a futuro podrían resultar lejanos o desconocidos.

Este es un proceso disruptivo en varios sectores académicos de Latinoamérica, pues si bien es cierto en muchos lugares del mundo es ya una práctica común, en los países en cuestión es una actividad que no todas las universidades lo aplican desde los primeros niveles de estudio o desde la lógica de investigación propia del Diseño Gráfico, un proceso que se aleja de los procesos tradicionales de investigación y se relaciona más con la experimentación y la vinculación con las comunidades para generar experiencias significativas, no solo para el contexto social, sino también para los estudiantes y docentes que participaron en el proceso. Además, tuvo una gran potencia académica, pues permitió articular los contenidos académicos con la vida misma, a través de la resolución de problemáticas reales propias de un entorno cercano y que dieron lugar a la apropiación del conocimiento, a la generación de conciencia social y sobre todo permitió a los estudiantes entender la manera en que su profesión aporta a la sociedad.

En el caso específico del Diseño Gráfico y de este proyecto en particular, la aplicación del método pretende que los estudiantes comprendan con claridad los fundamentos del diseño ligados a la construcción de propuestas gráficas efectivas y asociadas a un proceso de responsabilidad social y profesional de los Diseñadores Gráficos, que les permita hacer tangible temas relacionados con valores, además que facilite la vinculación del Paradigma Pedagógico Ignaciano4, pues se contextualiza al permitir que el estudiante se sitúe en el lugar mismo donde se presenta el problema, se genera experiencias al impulsarlos a relacionarse con las personas y descubrir los aspectos que dan lugar a la problemática identificada,

4. Comprende al modelo de educación con la pedagogía inspirada en San Ignacio de Loyola, que direcciona a las instituciones educativas que forman parte de la Compañía de Jesús y que se implemente desde 1993, cuyo propósito es generar un nuevo modelo educativo que promueva el cambio social y se pongan en práctica los valores del evangelio y la dignidad humana; para ello plantea cinco etapas: situar la realidad en su contexto, experimentarla vivencialmente, reflexionar sobre las experiencias adquiridas, actuar consecuentemente y evaluar las acciones y procesos ejecutados, todas ellas llevadas a cabo en un entorno de confianza y respeto donde el docente acompaña en el proceso y se le da oportunidad al estudiante para que vaya descubriendo la verdad por si mismo, y construya significados nuevos y más complejos.

Umática. 2021; 4. https://doi.org/10.24310/Umatica.2021.v3i4.12241 
así como reflexionar, pues no basta con conocerlos, también es necesario analizarlos, entenderlos y dar lugar a un pensamiento metacognitivo; por otra parte, todos estos aspectos se llevan a la práctica (acción), donde se da lugar a la toma de decisiones en función de datos e investigaciones reales y se propende el desarrollo de un pensamiento creativo; y finalmente, el proceso termina con una etapa de evaluación, donde más que tener un carácter sumativo, busca que el estudiante adquiera un pensamiento crítico, que sepa identificar la efectividad o no de sus decisiones y aquellos aspectos en los cuales quizá su proyecto requirió mayor esfuerzo. Con todo ello se lograría una formación integral que propenda no solo la formación de buenos profesionales, sino también personas con valores y responsables para consigo mismas y con la sociedad.

Por otra parte, debido a que las dos universidades participantes en este proyecto se encuentran ligadas al aprendizaje del Diseño Gráfico bajo una modalidad basada en proyectos, se torna mucho más fácil vincular los conocimientos de otras materias del nivel, aun cuando estas no se encuentren inmersas directamente en el proceso.

Previo al trabajo conjunto, desde cada universidad se promovió que los estudiantes realicen una investigación preliminar, donde a través de una exploración individual que no comprometa su seguridad, les permita recabar información que les ayude a identificarse con sus respectivas ciudades, Distrito Metropolitano de Quito y la ciudad de Cali, y reconocer los aspectos propios de su cultura y entorno social. Esta recopilación de información en el caso de la PUCE se podía realizar mediante videos, documentales, reseñas, entrevistas virtuales, experiencias de familiares y conocidos, textos, que les ototgaron los insumos informativos para que luego construyeran un desktop walkthrough $h^{5}$, como se puede observar en el ejemplo de la figura 1, para evidenciar su investigación vinculada al funcionamiento de los negocios que expenden productos tradicionales de bajo costo en estos sectores.

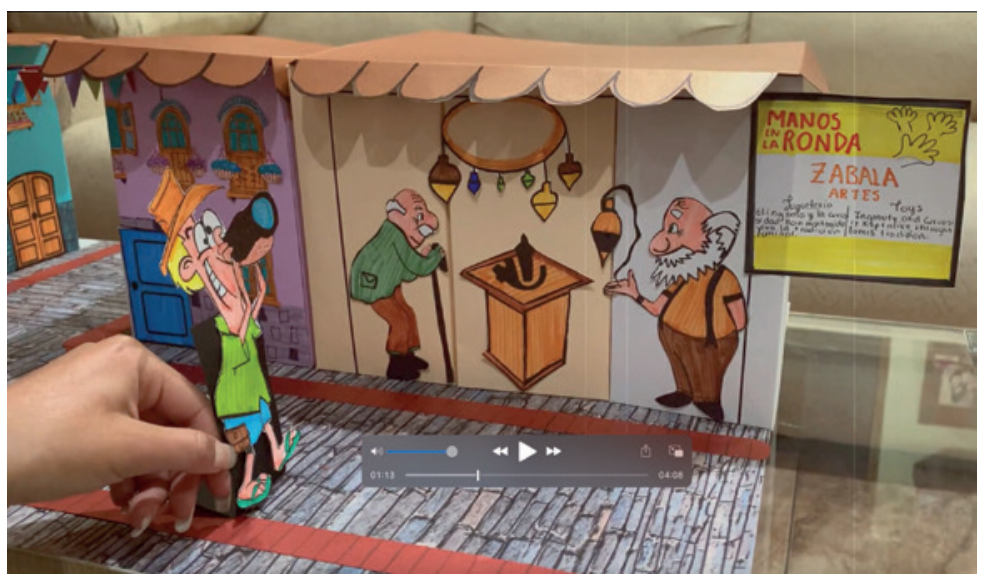

Fig. 1. Exploración individual. 2020. Fotografías extraídas de trabajos de estudiantes de primer nivel, primer semestre 2020 de la Pontificia Universidad Javeriana (PUJ) de Cali y Pontificia Universidad Católica del Ecuador (PUCE).

5. Consiste en la construcción de un escenario a pequeña escala con cualquier tipo de material que le permita representar entornos y situaciones de la vida real y explicar la forma en que funciona un servicio y su experiencia implícita y que les permita comprender mejor esa realidad.

Umática. 2021; 4. https://doi.org/10.24310/Umatica.2021.v3i4.12241 
Fig. 2. Metodología Colores por la Vida. 2017. Documento del Módulo III del Diplomado en Diseño e Innovación social dictado por docentes de la Pontificia Universidad Javeriana de Cali.
Una vez realizada esta investigación individual, se dio inicio al trabajo conjunto que se ejecutó en un período de cinco semanas aplicando el método Colores por la vida, que consta en la figura 2, cuyas fases fueron explicadas y aplicadas de la siguiente manera:

\section{MODELO COLORES POR LA VIDA}

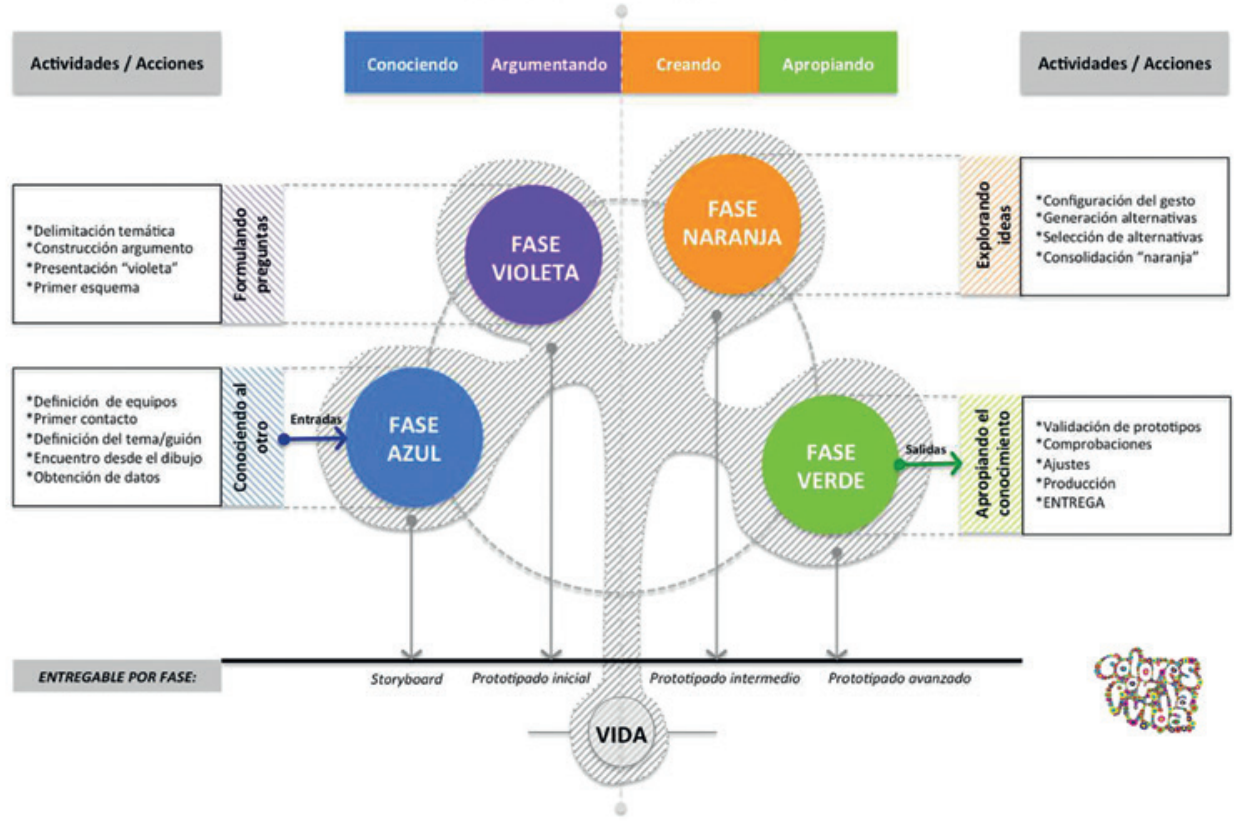

Fase 1: Conociendo al otro

Esta fase se ejecutó en la primera semana del proyecto, en ella se presentaron a los estudiantes y docentes, como se observa en la figura 3 , se contextualizó la iniciativa COIL, se dio a conocer la propuesta de trabajo, así como su modalidad; además, se realizó una dinámica en la que se buscó el acercamiento entre estudiantes y un primer contacto con el ámbito de abordaje del proyecto.

En esta dinámica se pidió que los estudiantes de Cali se describan a ellos mismos y luego a como veían a Quito y sus habitantes y lo mismo se hizo con los estudiantes de Quito; en resumen, las apreciaciones fueron muy cercanas a lo que la mayoría de las personas podríamos creer de estas ciudades; Cali, una ciudad llena de color, algarabía, gente alegre, fiesta continua, música en cada esquina, ropa ligera, el típico ambiente costero de Latinoamérica; por su parte Quito, una metrópoli llena de contrastes, con un centro histórico lleno de historia, procesos culturales de alto impacto, con gente amable pero a su vez más callada, recatada, con costumbres mucho más tradicionalistas y poco arriesgadas, más formal, profundamente religiosa y con un entorno climático bastante frío. Como se puede apreciar en el ejemplo de la figura 4, dos ciudades marcadas con grandes contrastes, donde el trabajo inicial se vio como un gran desafío. 

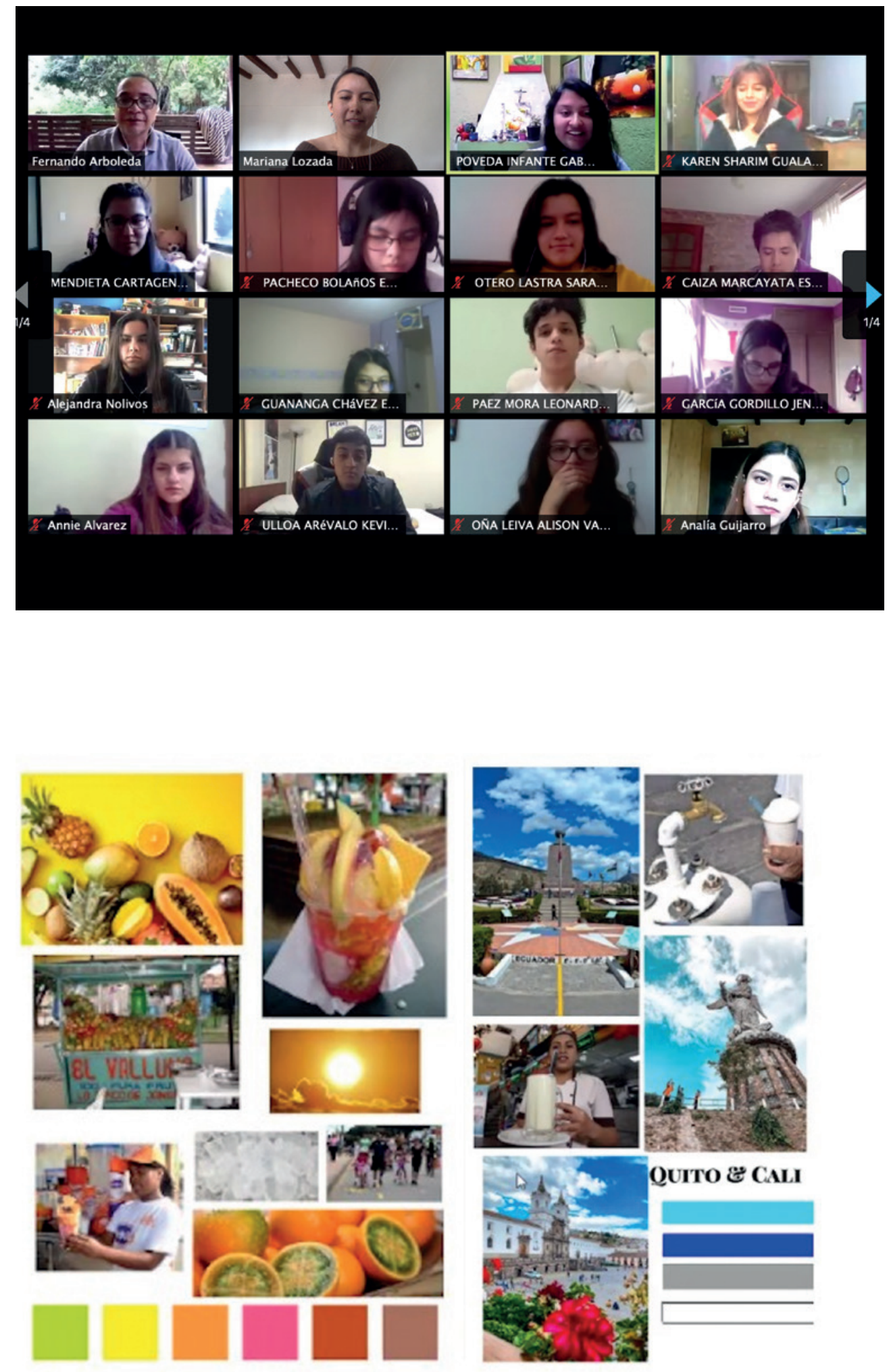

Fig. 3. Primera

reunión de trabajo

PUJ Cali-PUCE
Fig. 4. Investigación visual de Quito y Cali. 2020.

Fotografías extraídas de trabajos de estudiantes de primer nivel, primer semestre 2020 de la Pontificia Universidad Javeriana (PUJ) de Cali y Pontificia Universidad Católica del Ecuador (PUCE). 


\footnotetext{
Fig. 5. Cuadro de similitudes $y$ diferencias. 2020. Fotografías extraídas de trabajos de estudiantes de primer nivel, primer semestre 2020 de la Pontificia Universidad Javeriana (PUJ) de Cali y Pontificia Universidad Católica del Ecuador (PUCE).
}
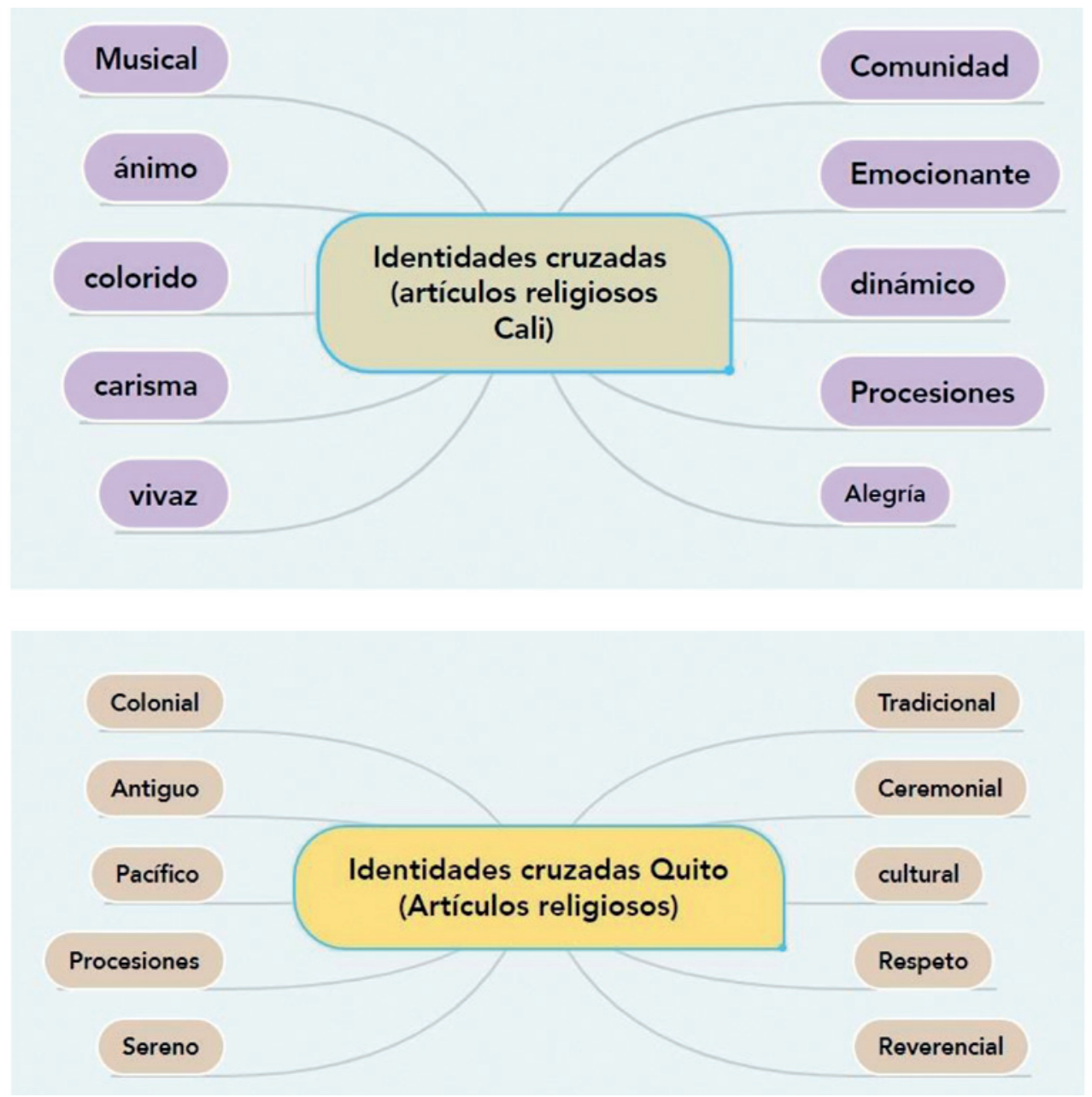

Luego se formaron 12 equipos en los que a cada uno se le asignaría una de las áreas de los negocios tradicionales de bajo costo mencionadas antes, con el fin de que iniciaran su proceso de investigación específico.

Al armar los grupos de trabajo se previó que en cada equipo exista una equidad de estudiantes de cada universidad y que den lugar a ciertos acuerdos de organización y distribución de actividades, pensando siempre en que no lo hagan de manera aislada, sino que se propenda siempre el trabajo conjunto, además que ellos mismos califiquen su nivel de participación y aporte en cada una de las actividades ejecutadas.

Una vez armados los equipos, se ejecutó el primer trabajo conjunto en el que se desarrolló una narrativa de similitudes y diferencias de ambas ciudades mediante un mapa mental y 


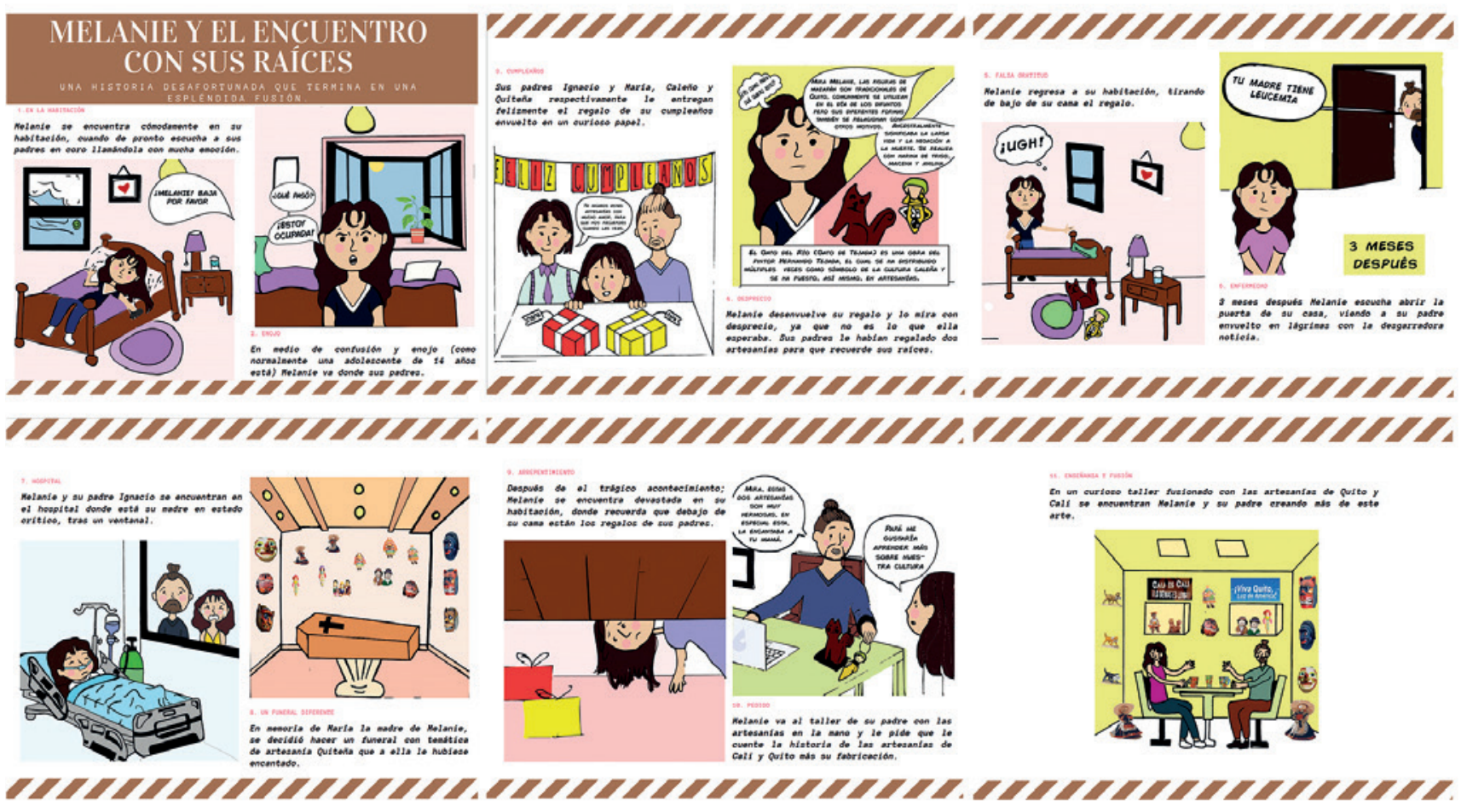

un storyboard, como se puede ver en las figuras 5 y 6 , una herramienta que permitió que esta etapa investigativa se muestre de forma más práctica, tangible, visible, y para ello se aplicó lo que sugiere Manzini (2015), la creación de historias, pues indica que "la narración es una herramienta que permite tratar temas complejos y mostrar a un tiempo la situación tal como es ahora y tal como nos gustaría que fuera en un futuro" (p. 160) y menciona que con ese intercambio de experiencias es posible transmitir sabiduría, creencias y valores acumulados.

El resultado del storyboard trajo consigo una serie de interesantes reflexiones que abrieron paso a un redescubrimiento de los mismos estudiantes y su entorno, pues lograron reconocer prácticas culturales propias que hasta ese momento las habían pasado por alto y las relacionaron con las prácticas de la otra ciudad, pudiendo identificar sus similitudes y diferencias y logrando hacer una introspección sobre el porqué de aquellas cuestiones.

Al exponer su tarea, como ejemplifica la figura 7 , los estudiantes fueron comentando sus apreciaciones sobre lo encontrado, en lo que se pudo evidenciar con toda claridad que ciertamente ambas ciudades tenían una serie de aspectos diferenciadores, pero en sí muchas de las costumbres eran bastantes similares o partían de la misma esencia cultural.
Fig. 6. Desarrollo del storyboard. 2020. Fotografías extraídas de trabajos de estudiantes de primer nivel, primer semestre 2020 de la Pontificia Universidad Javeriana (PUJ) de Cali y Pontificia Universidad Católica del Ecuador (PUCE) 
Fig. 7. Presentación del proyecto

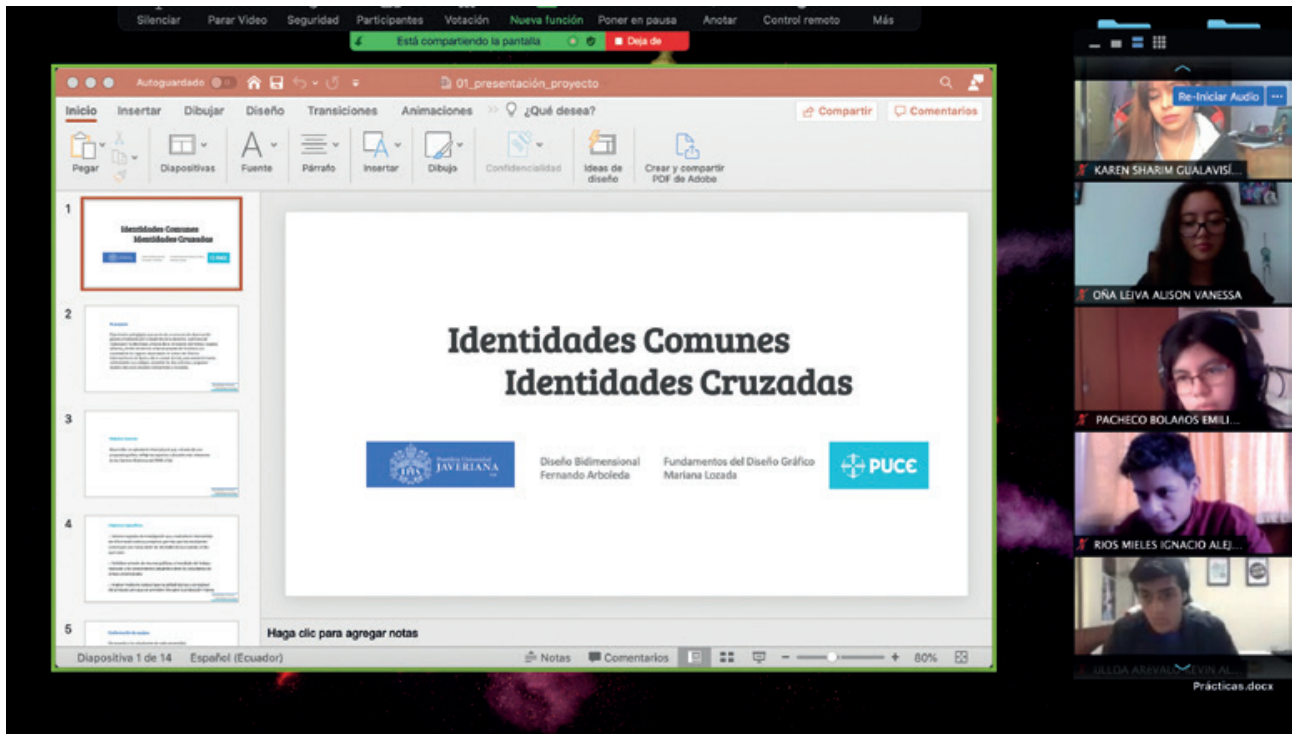

Es así que por ejemplo, en el caso de las procesiones religiosas, en Cali eran bastante alegres, coloridas y estaban acompañadas de baile y algarabía, mientras que en Quito eran muy ceremoniales, con varias expresiones de condolencia y reverencia, sus cánticos y su paso por las calles era más bien lento, con colores oscuros y en algunos casos lágrimas y largas plegarias; pero en ambos se superponía el sentido de adoración a un ser supremo, se evidenciaba el sincretismo cultural de Latinoamérica y algunos elementos propios de esa celebración, tales como velas, crucifijos, rosarios o estampitas, así como la propia dinámica comercial que rodea este tipo de celebraciones.

Igual sucedió en otros ámbitos, como en el caso de la comida, donde los nombres y presentaciones eran más o menos los mismos, como el canelazo - un hervido de naranjilla, canela y puntas- o la fritada en Quito o fritanga en Cali, donde el ingrediente principal, la carne de cerdo estaba presente en ambos platos, pero lo que variaba un poco eran los ingredientes de acompañamiento, pero en sí la base culinaria era muy similar y la preparación también.

$O$ en el caso de los juegos tradicionales, donde incluso muchos de ellos tenían el mismo nombre solo que los parámetros de juego variaban, pero manteniendo siempre ese sentido de unión familiar o social, disfrute al aire libre y la algarabía propia de este tipo de dinámicas sociales.

Así mismo en cuanto a las expresiones artísticas, donde hay una evidente diferencia entre la música rápida y alegre de Cali con la romántica y hasta nostálgica de Quito, pero ambas presentes en medio de expresiones callejeras como los retratistas, titiriteros o el olor 

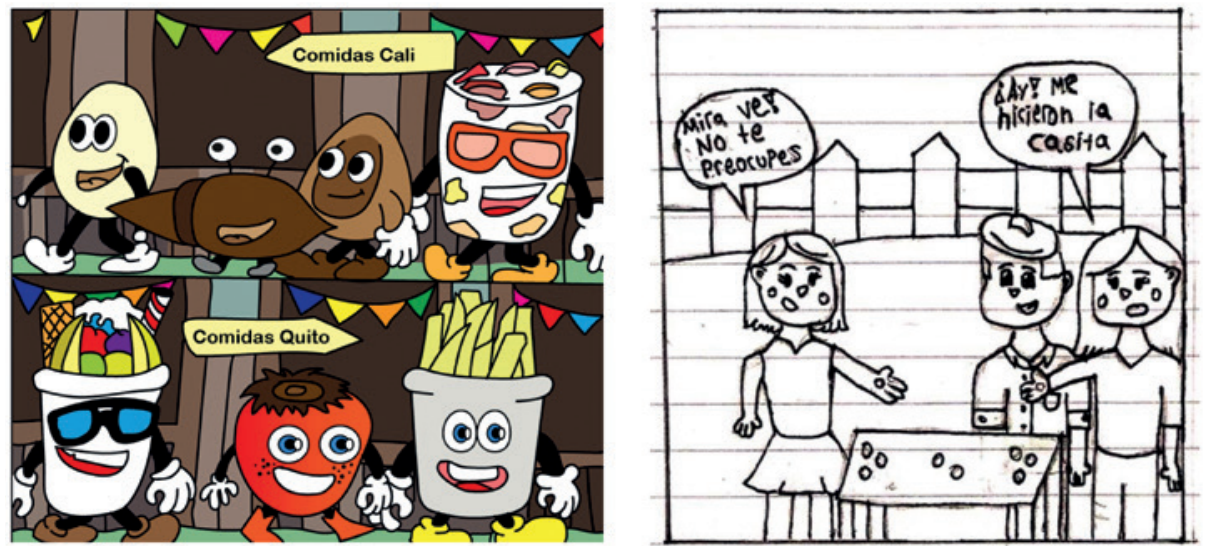

Fig. 8. Representación gráfica de similitudes $y$ diferencia. 2020.

Fotografías extraídas de trabajos de estudiantes de primer nivel, primer semestre 2020 de la Pontificia Universidad Javeriana (PUJ) de Cali y Pontificia Universidad Católica del Ecuador (PUCE).
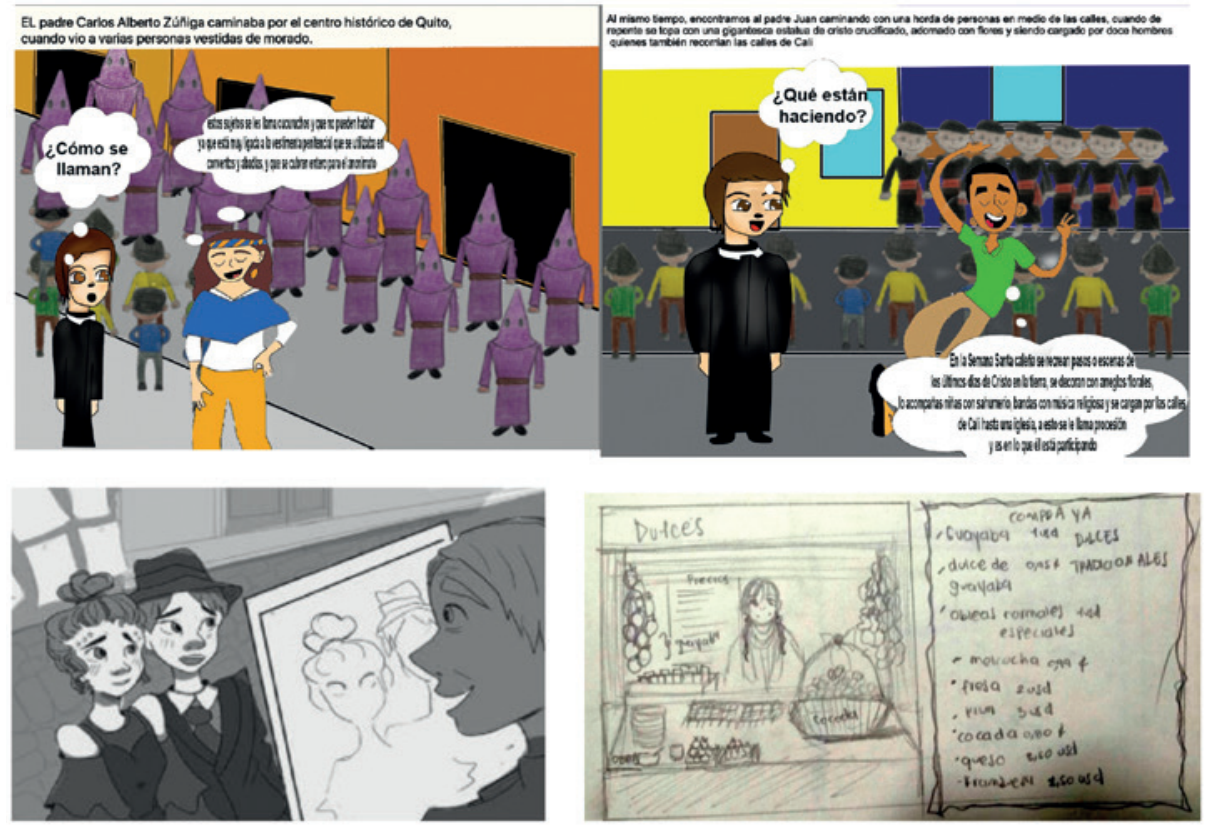

de los dulces tradicionales muy similares en ambas ciudades y la mirada expectante de los transeúntes que se detienen por largo tiempo y luego le regalan una monedita a aquel artista que los entretuvo por un momento.

En la figura 8 se muestran ejemplos de imágenes que formaron parte de los storyboards y que reflejan algunas de estas similitudes y diferencias identificadas entre ambas ciudades e incluso la jerga característica de cada una, con ello se completó el análisis de los códigos visuales que dieron paso a la propuesta creativa. 
Fig. 9. Grupo de trabajo en la elaboración de primera parte de la memoria. 2020. Fotografías extraídas de trabajos de estudiantes de primer nivel, primer semestre 2020 de la Pontificia Universidad Javeriana (PUJ) de Cali y Pontificia Universidad Católica del Ecuador (PUCE).

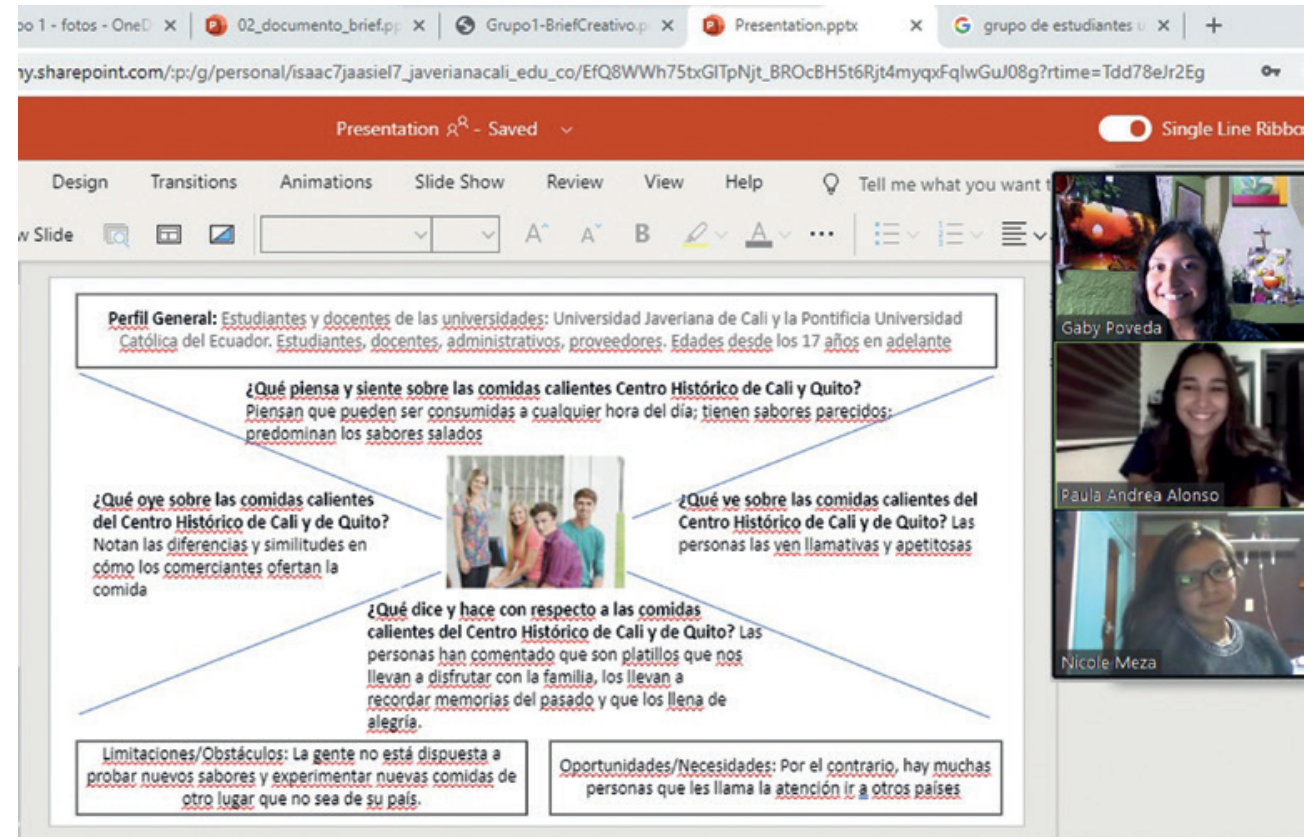

Fase 2: Formulando preguntas

Esta fase se llevó a cabo durante la segunda semana y en ella se realizó la investigación más profunda de cada tema, tanto del contexto como de los aspectos teóricos que se vinculaban a la temática, además del diálogo y reflexión que dieron lugar a la construcción de la primera parte de la memoria de trabajo, además de la elaboración de un brief de diseño que les permita a los estudiantes tener las ideas más claras y organizadas previo a la etapa creativa.

Cabe recalcar que en esta etapa también, como reflejan las figuras 9 y 10, se indagó sobre el público objetivo y aquellos aspectos que permitirían generar un mensaje gráfico mucho más preciso, lo que quizá fue uno de los grandes desafíos del trabajo, pues al tener limitaciones de acceso físico a los diferentes entornos y personas, fue necesario recurrir a otro tipo de estrategias o herramientas que les permitieran obtener mayor información, en este caso algunos de ellos realizaron encuentros Zoom o entrevistas a las personas que podrían aportar a su investigación y posteriormente cruzaron información, entendiendo que como se menciona en el documento Diseño Centrado en las personas de IDEO (S.f.), "La investigación para el diseño es útil no sólo para entender a las personas sino también para situar los comportamientos individuales en el contexto y en la comunidad que los contienen." (p.42)

En esta fase se promovió la escucha, la vinculación con los actores directos y el enlace a sus historias, relatos y vivencias, así como a la memoria histórica y social, pues a pesar del distanciamiento social, era importante que los estudiantes pudiesen sentir por si mismos estas vivencias, aprecien su riqueza propia y sean capaces de diferenciarla o relacionarla con la realidad de otro entorno, conexiones que les permitiría posteriormente generar un solo producto que represente a ambos entornos. 


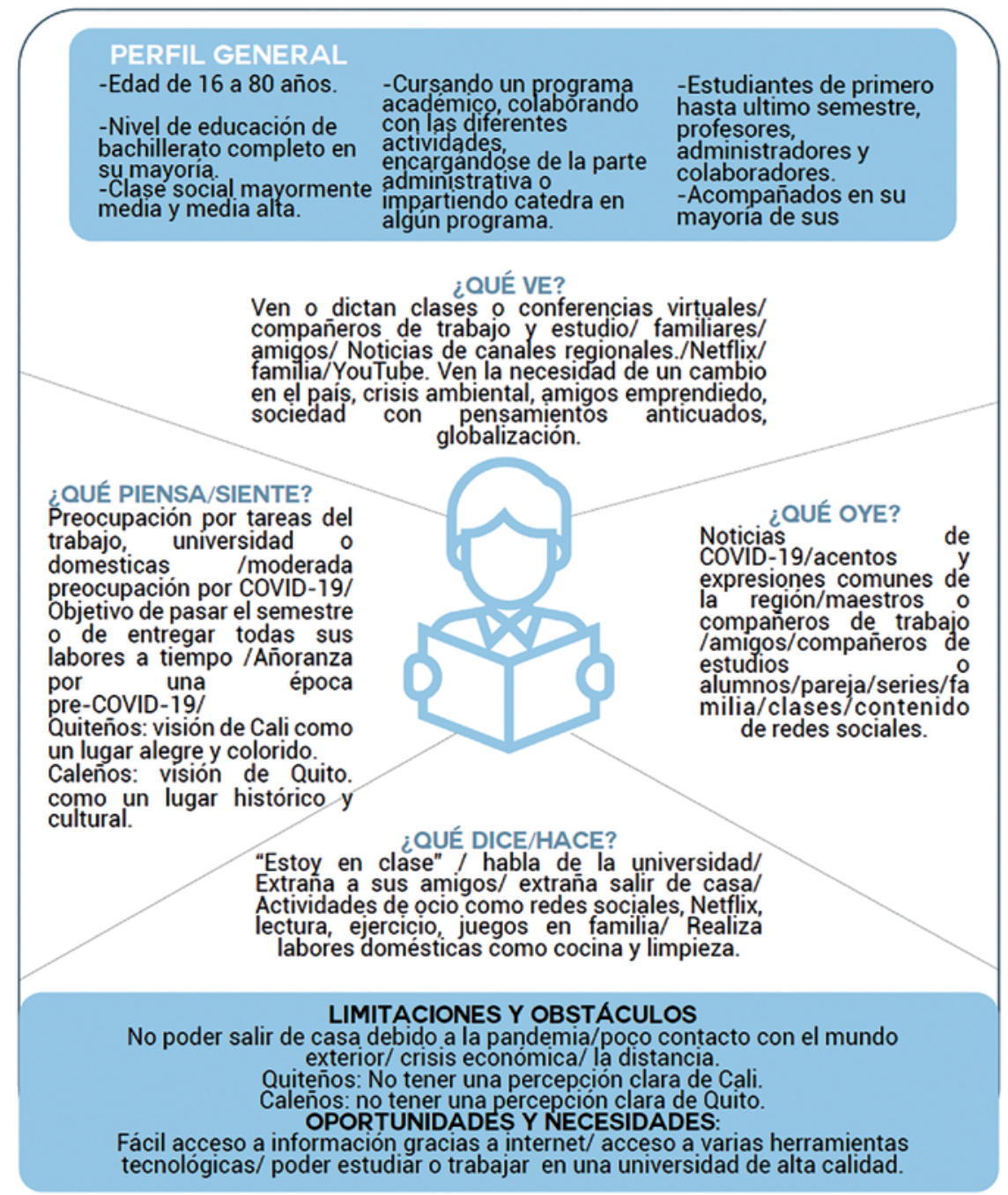

Fig. 10. Mapa de empatía. 2020. Fotografías extraídas de trabajos de estudiantes de primer nivel, primer semestre 2020 de la Pontificia Universidad Javeriana (PUJ) de Cali y Pontificia Universidad Católica del Ecuador (PUCE).

Como resultado, los estudiantes pudieron identificar que al igual que las prácticas sociales y culturales, si bien es cierto las formas de ser y los modelos de vida distaban bastante entre los caleños y los quiteños, siendo los primeros más abier tos, joviales y dinámicos, mientras que los quiteños tienden a ser más serios, formales y recatados, pero al mismo tiempo mantienen en su forma de ser y actuar ciertos rasgos que nos hacen similares, tales como el vínculo cercano con el otro, la priorización de la familia y el esfuerzo por mantener viva la herencia cultural, la necesidad de pertenencia, así como las lógicas propias del actuar cotidiano, aspectos que se fueron identificando a través de las preguntas que cada grupo se fue cuestionando.

Al final de esta fase se realizó la presentación del primer esquema de información que les ayudaría a los estudiantes a dar inicio con la etapa creativa. 


\section{Fase 3: Explorando ideas}

Esta fase se generó en las semanas tres y cuatro del proyecto e inició con el proceso creativo, específicamente las actividades de conceptualización de la propuesta gráfica, para luego elaborar un moodboard, como reflejan las figuras 14, 15 y 16, con los referentes visuales que dieron paso al desarrollo gráfico y los primeros bocetos, así como el desarrollo de la propuesta definitiva.

Para este proceso los estudiantes partieron de responder a preguntas fundamentales (figura 12) y la identificación de palabras claves que se obtuvieron de la investigación preliminar y que se organizaron a través de un brainstorming (figura 11 y 13), que derivó en la conformación de frases detonantes, de las cuales se seleccionó la mejor, se la depuró, fundamentó y con ella se trabajo la base conceptual.

Una vez definido el concepto de diseño, los equipos elaboraron un moodboard en el que identificaron todo tipo de aspectos visuales que pudiesen transmitir correctamente el mensaje establecido en la frase detonante.

El contar con este proceso de conceptualización y generación de moodboard facilitó el desarrollo de los bocetos, los que fueron depurándose en varias ocasiones hasta llegar a la idea final, la que tuvo una presentación preliminar para definir las últimas correcciones.

Fig. 11. Desarrollo del brainstorming. 2020. Fotografías extraídas de trabajos de estudiantes de primer nivel, primer semestre 2020 de la Pontificia Universidad Javeriana (PUJ) de Cali y Pontificia Universidad Católica del Ecuador (PUCE).

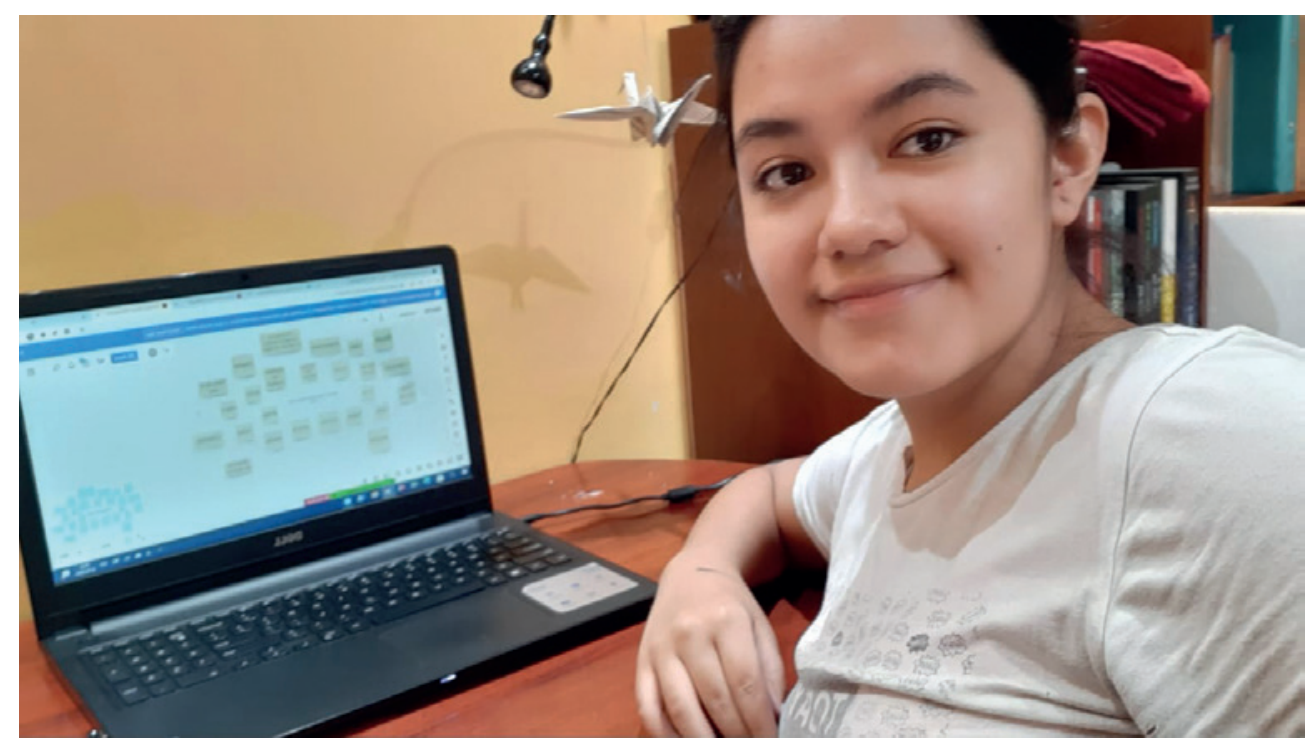




\section{Objetivo Comunicacional}

NECESIDAD: Se desconoce el valor y la relación que hay entre el arte callejero de Cali y Quito, y no existe una representación conjunta de estos en un mismo espacio.

OBJETIVO: Crear la página del mes de octubre de un calendario en el cual se visibilicen las similitudes del arte callejero caleño y quiteño.

¿UÉ ES?: Es una pieza gráfica en la cual se representan varios de los artistas que se ven en estas dos ciudades y que conviven en un mismo espacio.
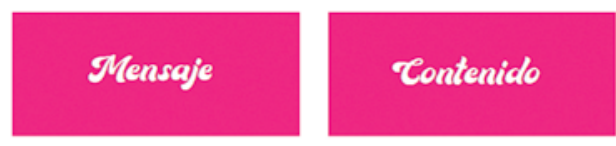

1. Nombre del mes.

QUÉ QUEREMOS COMUNICAR:

El calendario busca ser útil y práctico mientras a su vez ilustra el arte en las calles de Cali y Quito.

\section{CUÁL ES EL} MENSAJE: A pesar de las diferencias geográficas culturales, Quito y Cali comparten la riqueza en el arte que se encuentra en sus calles.
2. Días.

4. Breve descripción de la temática.
3. llustración.

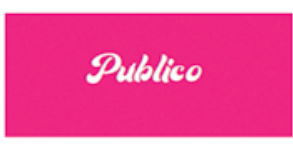

A ÓUIEN NOS DIRIGIMOS: Personas entre 17 y 70 años, estudiantes de primer a ultimo semestre, docentes , administrativos y colaboradores en las universidades. CÓMO SON: Directos, autónomos, trabajan por causas sociales o tienen un empleo dentro o por fuera de la universidad. Tienen planeas a futuro y se encuentran viendo o dictando clases o conferencias virtuales. DÓNDE ESTÁN: La mayor parte del tiempo se encuentran en casa. En otras ocaciones en la universidad o en el trabajo.

\section{DISEN̄O}

FIGURA I: PENSAMIENTO IRRADIADO

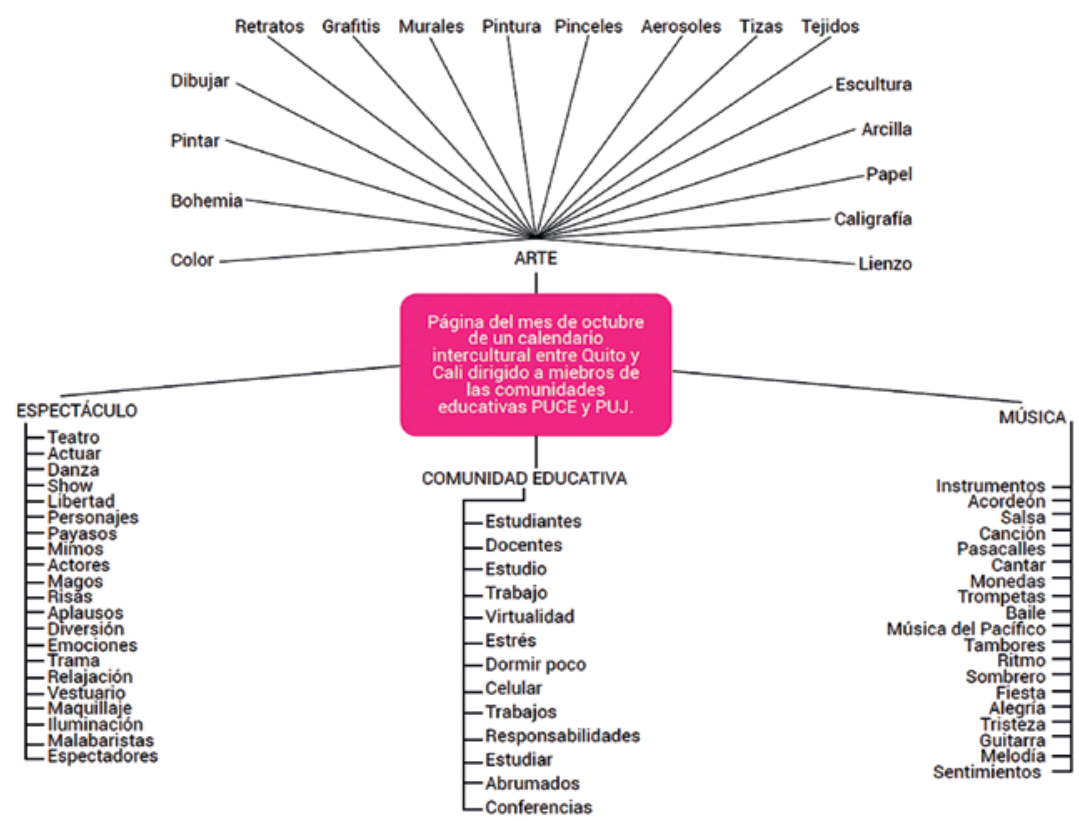

Fig. 13. Pensamiento

irradiante. 2020

Fotografías extraídas de trabajos de estudiantes de primer nivel, primer semestre 2020 de la

Pontificia Universidad Javeriana (PUJ) de Cali y Pontificia Universidad Católica del Ecuador (PUCE). 


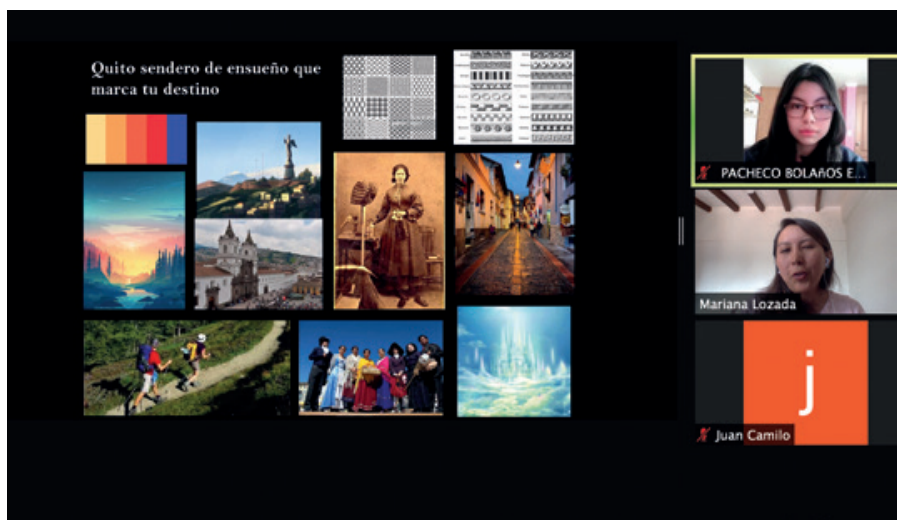

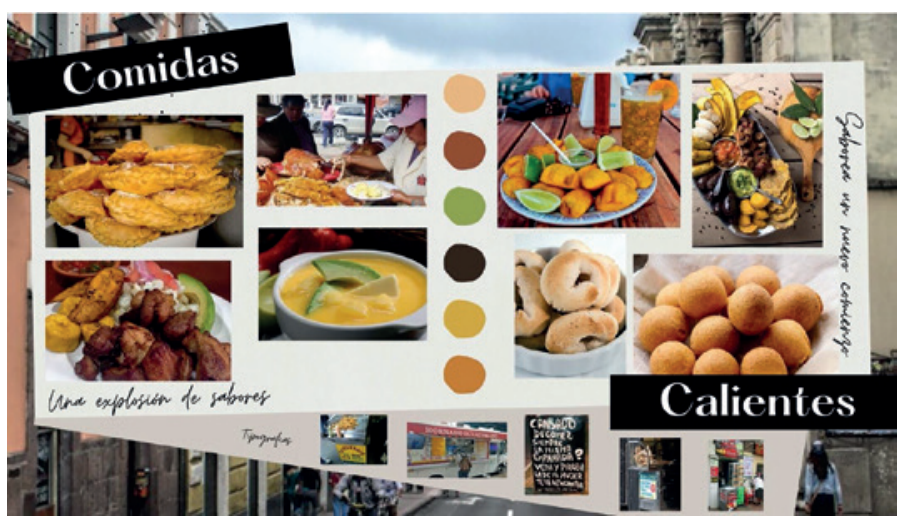

Fig. 14. Ejecución del moodboard. 2020.

Fotografías extraídas de trabajos de estudiantes de primer nivel, primer semestre 2020 de la Pontificia Universidad Javeriana (PUJ) de Cali y Pontificia Universidad Católica del Ecuador (PUCE).

Fig. 15. Moodboard comidas calientes. 2020. Fotografías extraídas de trabajos de estudiantes de primer nivel, primer semestre 2020 de la Pontificia Universidad Javeriana (PUJ) de Cali y Pontificia Universidad Católica del Ecuador (PUCE).
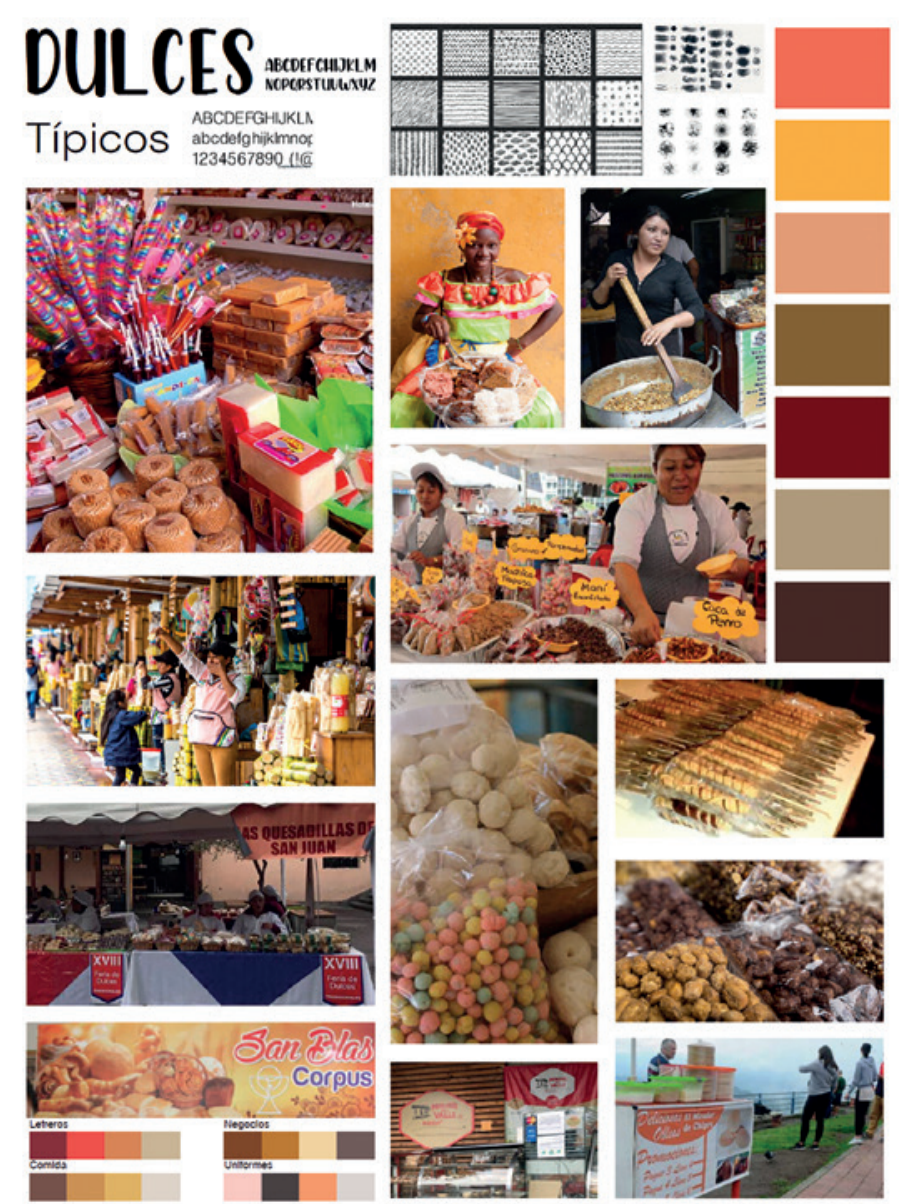

Fig. 16. Moodboard dulces tradicionales. 2020. Fotografías extraídas de trabajos de estudiantes de primer nivel, primer semestre 2020 de la Pontificia Universidad Javeriana (PUJ) de Cali y Pontificia Universidad Católica del Ecuador (PUCE). 


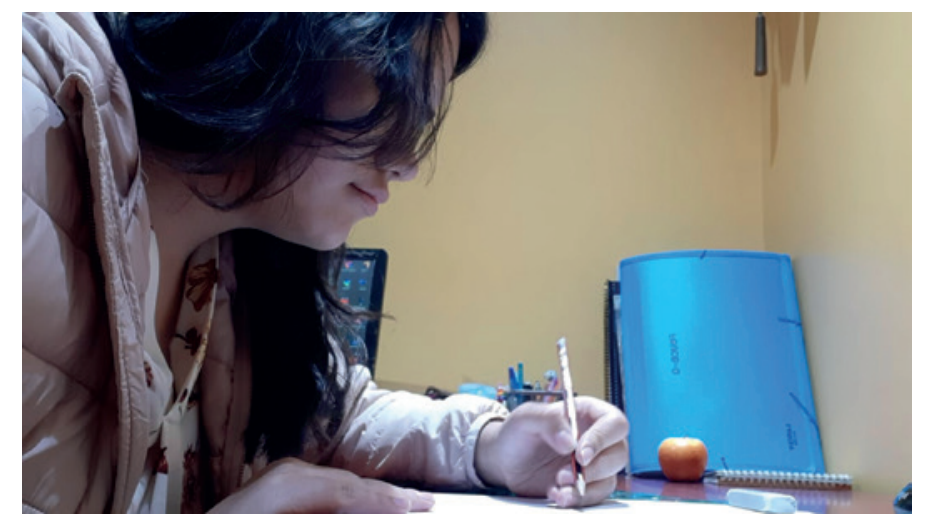

Fig. 17. Realización bocetos. 2020.

Fotografías extraídas de trabajos de estudiantes de primer nivel, primer semestre 2020 de la Pontificia Universidad Javeriana (PUJ) de Cali y Pontificia Universidad Católica del Ecuador (PUCE).

Fig. 18. Revisión de bocetos y propuesta final. 2020. Fotografías extraídas de trabajos de estudiantes de primer nivel, primer semestre 2020 de la Pontificia Universidad Javeriana (PUJ) de Cali y Pontificia Universidad Católica del Ecuador (PUCE).

Fig. 19. Proceso de diseño. 2020. Fotografías extraídas de trabajos de estudiantes de primer nivel, primer semestre 2020 de la Pontificia Universidad Javeriana (PUJ) de Cali y Pontificia Universidad Católica del Ecuador (PUCE).
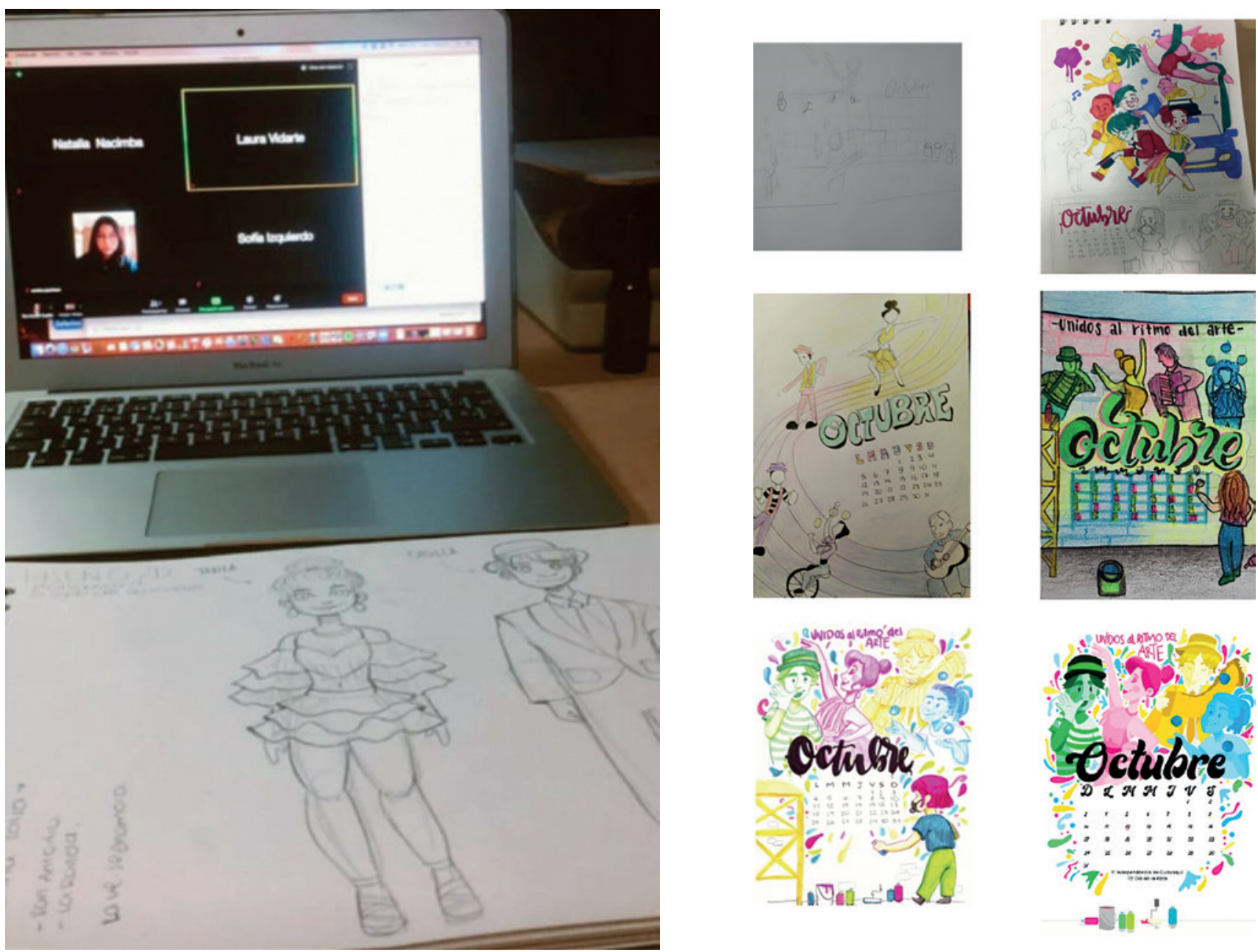
Fig. 20. Proceso general. 2020. Fotografías extraídas de trabajos de estudiantes de primer nivel, primer semestre 2020 de la Pontificia Universidad Javeriana (PUJ) de Cali y Pontificia Universidad Católica del Ecuador (PUCE).

\section{Fase 4: Apropiando el conocimiento}

Esta es la última fase del proceso y se llevó a cabo en la quinta semana de trabajo, donde los estudiantes presentaron sus propuestas gráficas, así como la memoria bitácora de trabajo y un storytelling de cinco minutos que relataba todo el proceso y la aplicación de la metodología.
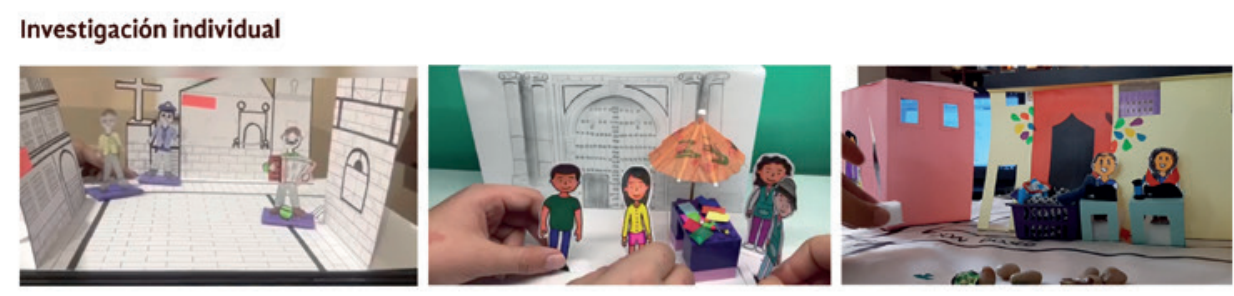

Investigación conjunta - identificacion de similitudes y diferencias

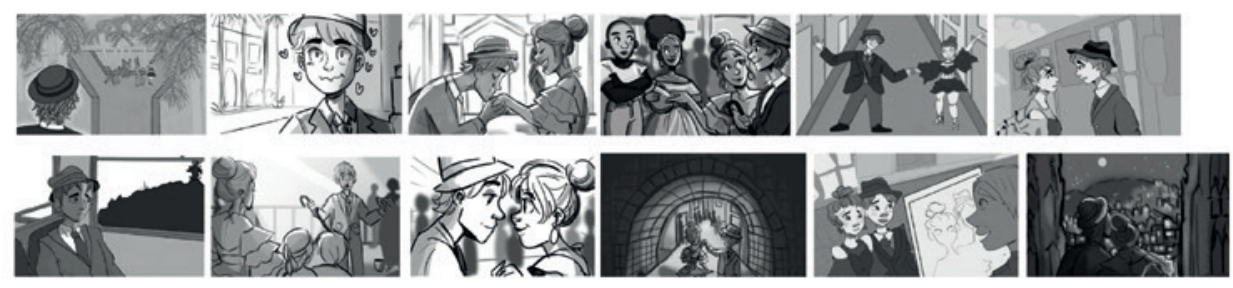

Conceptualización y bocetos
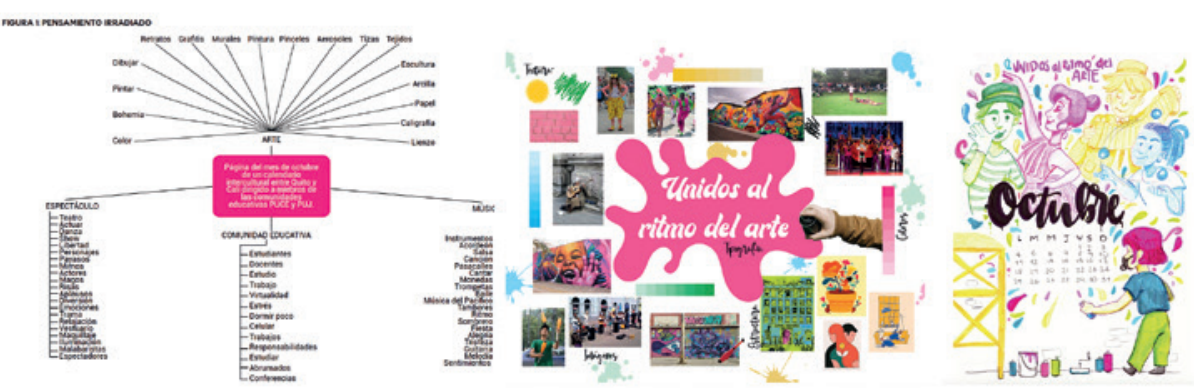

Propuesta final

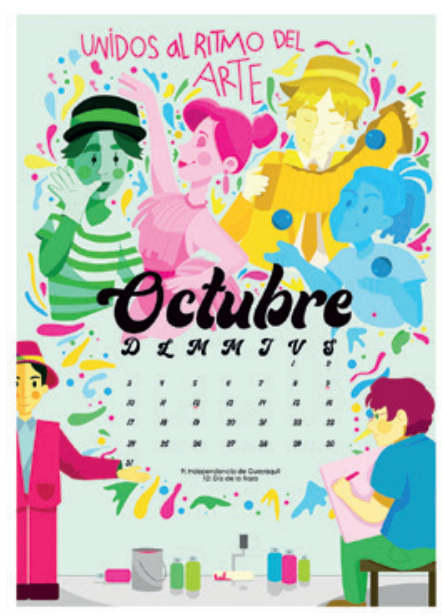

Umática. 2021; 4. https://doi.org/10.24310/Umatica.2021.v3i4.12241 
A continuación, se presentan algunos de los trabajos realizados por los grupos de estudiantes, en el caso del primero, correspondiente al grupo de comidas calientes que parafraseando sus palabras mencionan que identificaron las comidas calientes más representativas y similares de ambas ciudades, sus texturas, patrones, representaciones gráficas de la vestimenta de los vendedores, sus utensilios y los lugares en los que se ofertan, tomando en consideración la cromática que rodea a este tipo de alimentos, además de códigos visuales muy representativos como la típica sombrilla de las ventas ambulantes y la tipografía que refleja los letreros hechos a mano.

Esto también sucede con el segundo y tercer diseño, donde se evidencia claramente los colores representativos del tema, los trazos, formas y comportamientos propios de dichos espacios, como es el caso de las bebidas frias, donde prima el contraste de colores luminosos, la celebración y el sol, así mismo en los dulces tradicionales es quizá el espacio donde más se evidencia el trabajo artesanal, los sitios de añoranza de la infancia, la armonía y el disfrute del tiempo libre, mientras que en la última imagen es más que evidente al alto contraste que existe entre la vestimenta de una ciudad y otra, el frío y lo cálido, lo tradicional y lo innovador, lo serio y lo festivo, pero siempre vistiendo a seres que en esencia son lo mismo.

Además, en esta etapa se premió a la estudiante ganadora de la portada de la agenda calendario, pues el diseño de este espacio se destinó a un concurso entre los estudiantes cuyo carácter fue autónomo, opcional y sin supervisión de los docentes.

Cabe recalcar que durante las cinco fases los estudiantes siempre contaron con el apoyo de los docentes de ambas universidades, tanto a través de dos tutorías a la semana como de tutorías individuales o por grupos. Este trabajo demanda un gran esfuerzo y tiempo de ambas partes, pero es una de las mayores posibilidades para ir depurando las propuestas.

En cuanto a los procesos de evaluación y análisis final, se aplicó la evaluación regular, en la que los docentes se reunieron para evaluar semanalmente avances; una autoevaluación en la que los estudiantes se calificaban tanto individualmente como en grupo respeto a su nivel de participación y aporte al trabajo y finalmente se realizó una comprobación en la que, a través de la presentación del producto al público objetivo, cada grupo pudo identificar las posibles mejoras para sus proyectos y reflexionar sobre sus aciertos y errores. 
Fig. 21. Algunos resultados del trabajo realizado. 2020.

Fotografías extraídas de trabajos de estudiantes de primer nivel, primer semestre 2020 de la Pontificia Universidad Javeriana (PUJ) de Cali y Pontificia Universidad Católica del Ecuador (PUCE).
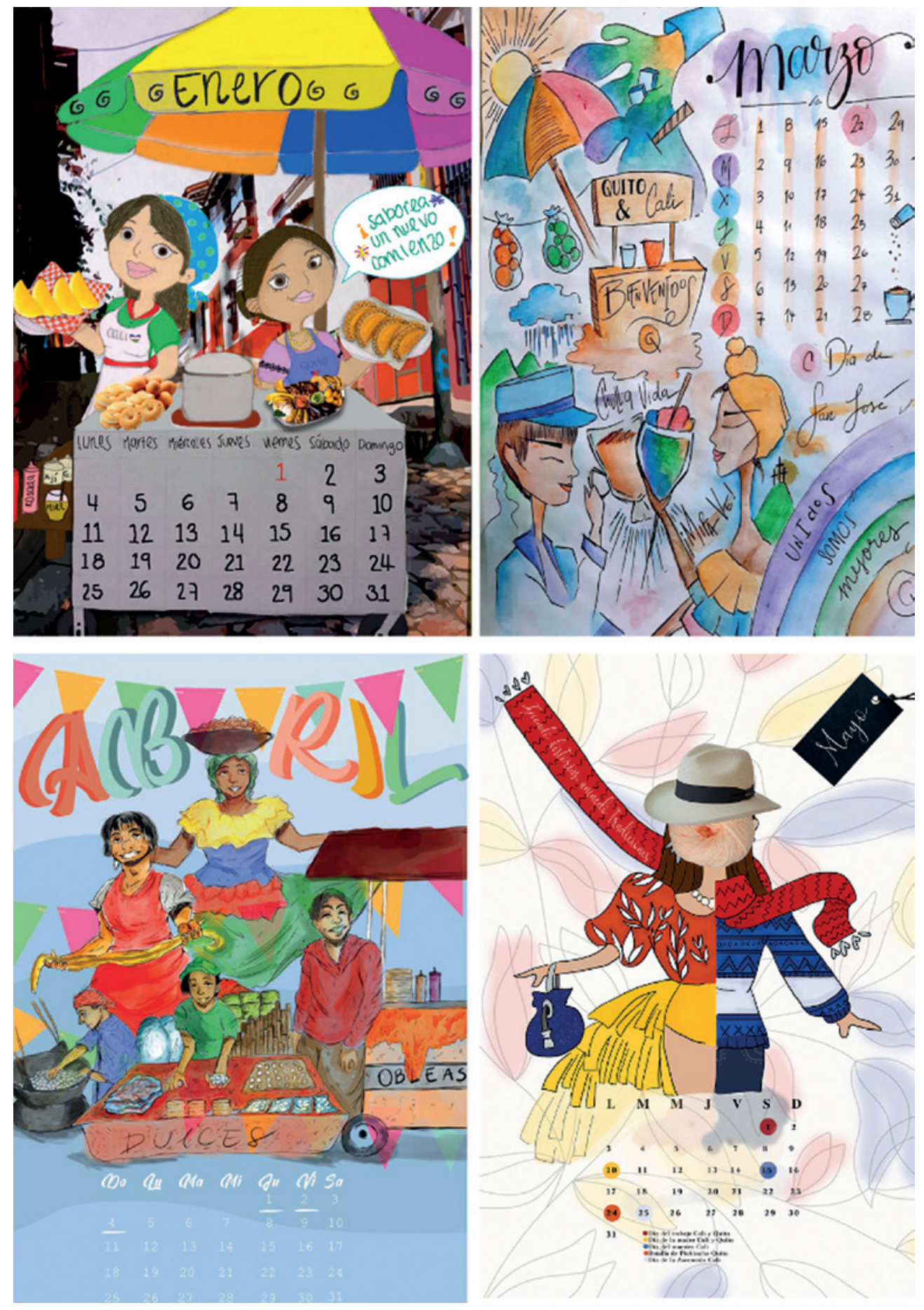


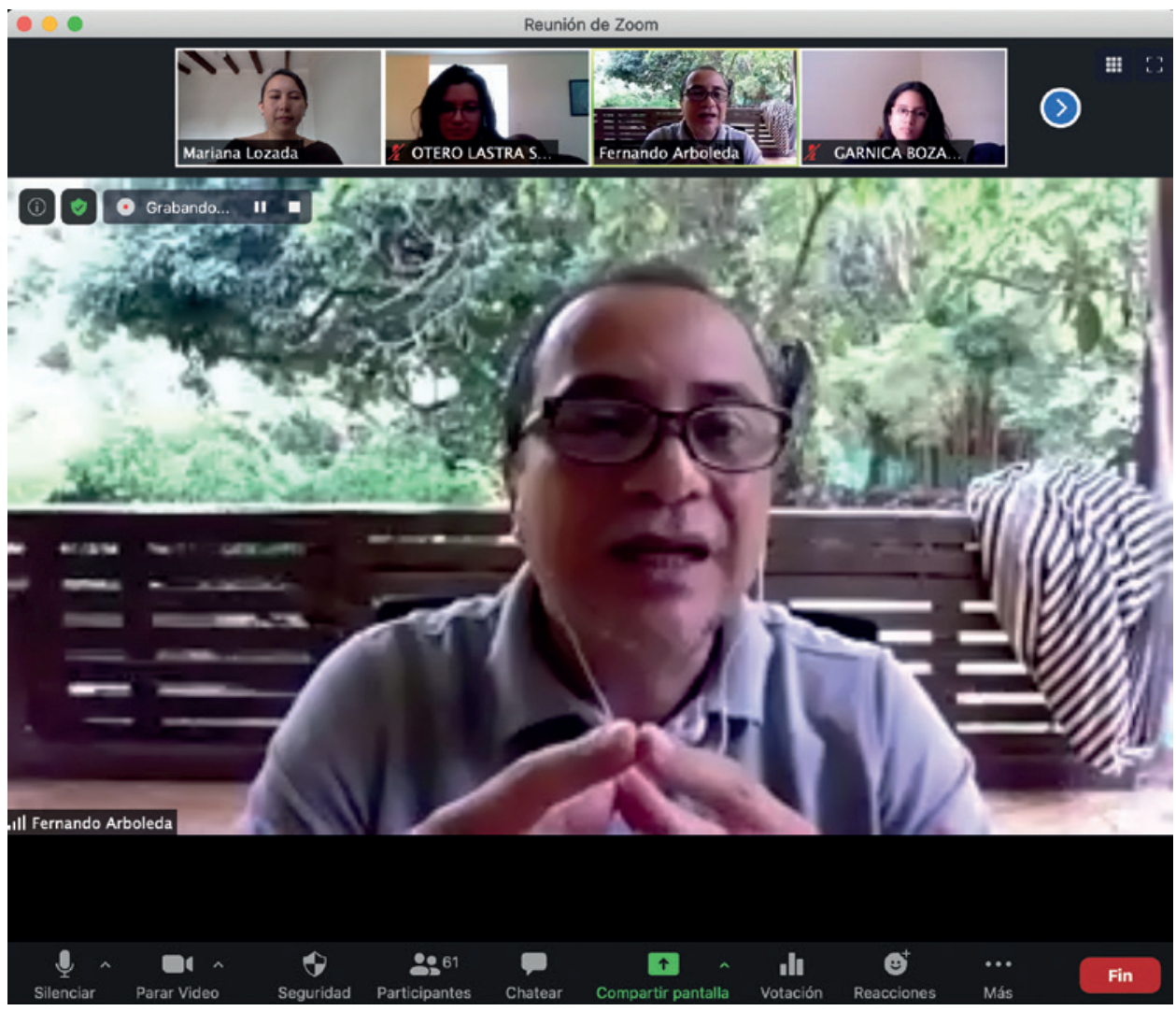

Fig. 22. Tutorías grupales

\section{Resultados}

Para la presentación los estudiantes entregaron una memoria que recopilaba todo el trabajo realizado durante las cinco semanas, así como un storytelling que relataba todo el proceso, además del diseño culminado, el que a futuro se aplicaría en el producto unificado.

Como producto final se culminó con el prototipo del Calendario 2021 denominado "Miradas escondidas del Centro Histórico de Quito y Cali", mismo que requiere algunas correcciones para terminar con la propuesta y poderla imprimir.

Además del resultado visual que se obtuvo con cada grupo de trabajo y la calidad de los resultados, que evidentemente es variada, es posible resaltar la capacidad de análisis e interpretación que lograron los estudiantes en el proceso y la habilidad para representarlo a través de una propuesta gráfica, pues como menciona Arfuch (S.f.) en su análisis de la imagen y experiencia, el poder de la imagen reside en su fuerza de representar, en el modo en que impacta a quienes la leen y el tipo de respuesta que suscita. En este punto los trabajos lograron tanto representar la identidad y colectiva de las ciudades en cuestión vinculándolas con efectividad a las memorias de sus habitantes, citando nuevamente a Arfuch (S.f.), se cumple con "Imágenes que confluyen en la percepción y en la configuración de identidades y subje- 
Fig. 23. Diseño final de la agenda calendario. 2020. Fotografías extraídas de trabajos de estudiantes de primer nivel, primer semestre 2020 de la Pontificia Universidad Javeriana (PUJ) de Cali y Pontificia Universidad Católica del Ecuador (PUCE).

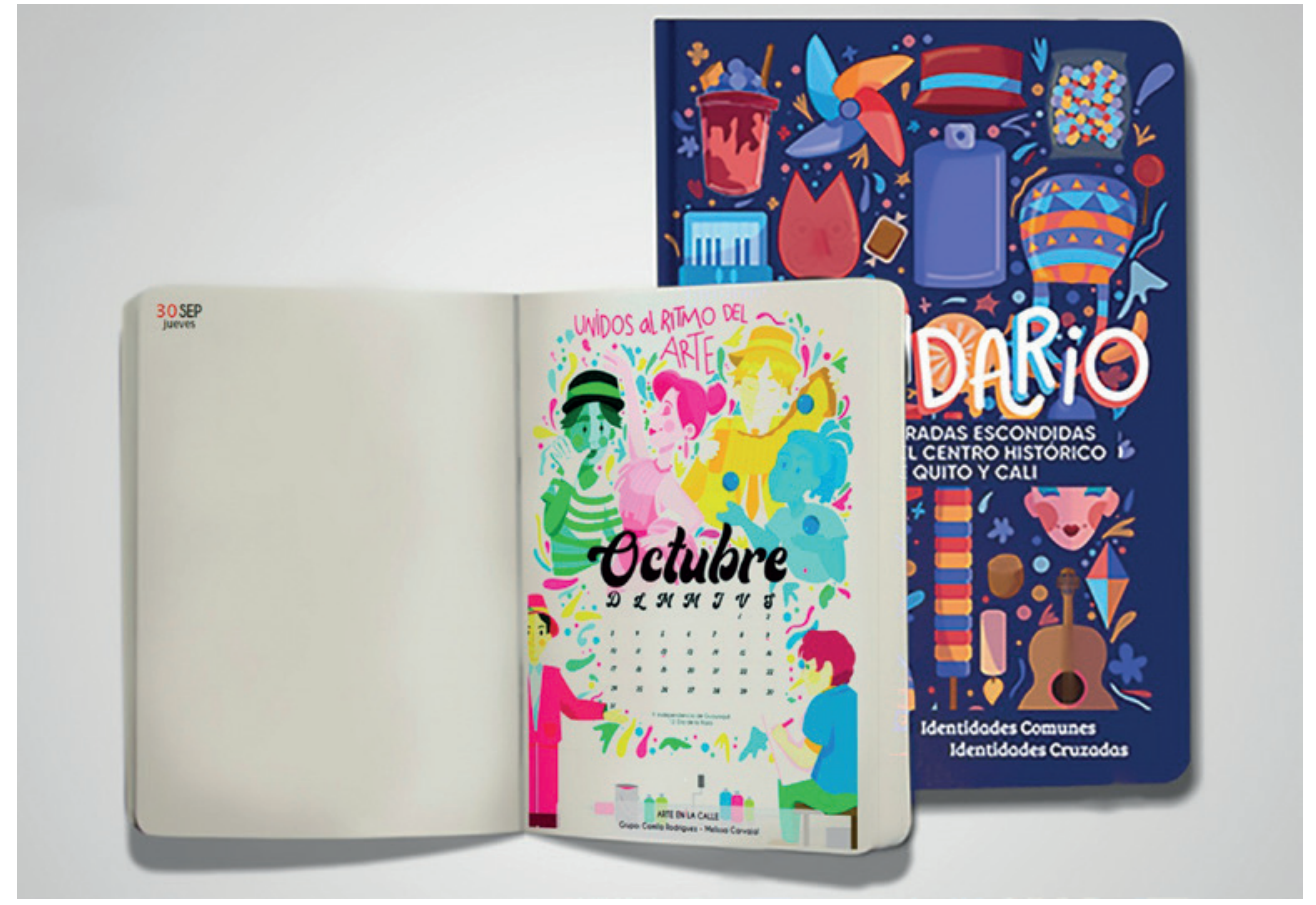

tividades, tanto en sus acentos individuales como colectivos. Y está además su relación con la memoria" (p.10)

Respecto a la validación por parte del público objetivo, aun cuando no hay un elemento gráfico, los estudiantes presentaron videos donde se mostraban las entrevistas y focus group que realizaron a varios representantes de su público objetivo, en las que se encontraron respuestas muy variadas, algunas evidenciaron que el mensaje se podía entender con claridad, mientras en otros casos se podía identificar algunas falencias gráficas que confundían al público objetivo, pero en medio de todo, lo importante fue que los estudiantes pudieron recibir dichos comentarios, reflexionar sobre sus aciertos y errores y exponer las consideraciones que tomarían en cuenta para mejorar sus propuestas gráficas.

Desde el punto de vista de los estudiantes fue explícito lo gratificante del proyecto, pues como ellos mencionan en videos de retroalimentación recopilados al final del proceso, si bien es cierto se generaron ciertos inconvenientes que debieron solventar, principalmente en cuanto a coordinación y apreciación directa de la otra realidad, al mismo tiempo les permitió vincularse con otros entornos sociales y generar una sinergia entre ellos, entablando lazos de amistad y trabajo que seguramente se volverán a conectar posteriormente, ya sea en la vida académica o en la profesional, además de lo importante de vincularse a problemáticas que los enfrente a un desafío real donde puedan aplicar los conocimientos adquiridos.

Desde el punto de vista docente, en el ámbito puramente académico se evaluaron aspectos como: cumplimiento de parámetros dados, nivel de investigación, capacidad de reflexión y redacción, nivel de innovación en el proceso de ideación, ajuste de las decisiones de diseño 
según los datos investigados, adaptación de los códigos visuales propios del tema al proyecto propuesto, terminados gráficos, criterio para la validación, capacidad de exposición y fundamentación de la propuesta: y en cuanto a la apreciación docente respecto al desempeño de los estudiantes, fue evidente su compromiso con el proyecto, pues a pesar de las dificultades de encuentros, los estudiantes buscaron las maneras para solventar sus dudas o para que los docentes aporten a sus propuestas, ya sea mediante tutorías individuales por Zoom, por correos electrónicos, a través de correcciones en la carpeta compartida e incluso mediante revisiones WhatsApp, considerando siempre los procesos de evaluación base de las disciplinas proyectuales que mencionan Mazzeo y Romano (2007), como son: las correcciones continuas a lo largo del proyecto, las correcciones en momentos específicos a modo de pre-entregas, las entregas parciales y las finales (p. 136)

Cabe recalcar que esta sinergia no se dio únicamente entre estudiantes, sino también con los docentes, pues se pudo evidenciar que los estudiantes no preguntaban únicamente al docente de su institución, sino que tuvieron la confianza de vincularse también con el otro docente para guías especializadas.

Por otra parte, como es conocido, ningún proyecto culmina tal y como se lo planificó, pues como bien menciona el Design Thinking for Educators de IDEO (S.f.), "Es el caso para tomar riesgos, probar cosas nuevas y evaluar si funciona o no". En el caso de este proyecto, se debieron solventar algunos inconvenientes vinculados a operatividad y a la deserción de varios estudiantes, pues la pandemia agravó la situación económica de varios hogares y tornó diferente a otros, lo que dio lugar a la generación de ciertos ajustes familiares, siendo uno de ellos el cambio o retiro de universidad de los jóvenes.

En este punto es importante aclarar que ambas metodologías tienen como base los parámetros fundamentales en cualquier proceso de diseño: investigación - ideación - diseño y validación, simplemente que el Design Thinking for Educators proveyó a los docentes de ciertas herramientas que enriquezcan el desarrollo de la clase, mientras que Colores por la vida dotó de herramientas para que los estudiantes puedan tener una conexión más fuerte con las comunidades a las que se vinculó el proyecto.

\section{Lecciones aprendidas}

A través de las evaluaciones cualitativas y cuantitativas del proyecto, se pudo identificar varios aspectos de mejora para próximos proyectos, entre ellas se encuentran:

- Debido al nivel de conocimiento de los estudiantes, sería mejor que el proyecto inicie unas semanas más tarde y dure por lo menos una semana más.

- Es necesario coordinar mejor los espacios de encuentro y el desarrollo de las actividades intermedias, propendiendo siempre la ejecución de estas a través de documentos guía claramente definidos.

- Debido a las restricciones de contacto físico con otras personas y entornos y por seguridad de los estudiantes, es necesario pensar con mayor detenimiento en las temáticas de 
los proyectos y la forma en que les permitirán a los estudiantes conectarse entre sí, con su entorno propio y con el entorno del otro.

- Desde el punto de vista operativo, aunque resulta difícil, es importante unificar los horarios de ambas materias, de tal manera que facilite las reuniones grupales.

- Respecto a las evaluaciones cuantitativas, también es necesario dar continuidad a una evaluación unificada equivalente de forma porcentual al sistema propio de cada universidad, aunque requieren la inclusión de rúbricas más detalladas.

Es así que al finalizar la descripción del proyecto, claramente se pone a la luz las premisas que menciona el Design Thinking for Educators de IDEO (S.f.) refiriéndose a las nuevas formas de trabajo en la educación:

- Confianza: pues, al entablar relaciones entre estudiantes y las comunidades, se impulsó la transformación en las formas de pensar y decidir sobre el diseño.

- Pertenencia: pues se promovió la valoración de la cultura propia como de la del otro grupo.

- Resilencia: reconociendo que aunque son pequeñas actividades, poseen un potencial para convertirse en algo más grande.

- Evidencia: Pues se logró la validación con los posibles comitentes y desde la misma disciplina.

- Colaboración: pues el trabajo en equipo y desde diferentes perspectivas les permitió tener una visión más amplia de tema y las soluciones gráficas.

Como se puede ver, cada uno de estos aspectos han sido puestos en práctica y aun cuando es un proyecto pequeño y de bajo alcance, seguramente será el punto de partida y la referencia que tendrán los estudiantes para propuestas más grandes y con un desafío mayor.

Oportunidades de mejora

Este tipo de proyectos demandan una coordinación y comunicación constante entre todas las personas implicadas en los procesos, pues esto favorecería el cumplimiento de los tiempos establecidos, de los objetivos planteados y por ende la correcta ejecución del producto esperado. En el caso de este proyecto, aun cuando se logró una buena coordinación, se pudieron evidenciar varios aspectos, sobre todo comunicacionales que podrían ser mejorados en una siguiente aplicación.

En el caso de los procesos de aprendizaje es necesario conocer con mayor profundidad sobre las mallas curriculares de cada universidad participante, así como el nivel de aprendizaje en el que se encuentran los estudiantes al momento de iniciar el proyecto, de tal manera que se prevean los aspectos en los cuales se pueden reforzar conocimientos o brindar mayor apoyo para equiparar la experiencia.

Quizá el desafío más grande en este tipo de proyectos es que los estudiantes comprendan que las dinámicas con comunidades no son iguales que las académicas y que por lo tanto deben prever y desarrollar procesos más flexibles y adaptables a esos contextos, sabiendo 
que en muchas ocasiones esas realidades podrían limitar o demorar el efectivo desarrollo de cada fase, pues como Bransford, J., Et. Al. (2000) citan a Talbert and McLaughlin "Hoy los estudiantes necesitan comprender el estado de sus conocimientos y aprovecharlos, mejorarlos y tomar decisiones frente a la incertidumbre...pues la sociedad visualiza graduados de los sistemas escolares que puedan identificar, resolver problemas y hacer contribuciones a la sociedad a lo largo de su vida, que muestren cualidades de experiencias adaptativas", con ello se logra que los estudiantes comprendan que el diseño no es un proceso que se sigue al pie de la letra, sino que tiene la capacidad de adaptabilidad de acuerdo a las diversas circunstancias.

Finalmente, es necesario que los estudiantes evidencien con mayor fuerza la vinculación de los usuarios con el producto, pues como menciona Vidal "A partir de ahora, nos interesa centrar la atención en cómo el diseño de cualquier rama, sea gráfico, de producto, de interiores o de moda, mediante la creación de espacios, imágenes, objetos u otros artefactos, conforma valores, intereses, expectativas y estilos de vida. Y estos son, a la vez, el marco, las condiciones de posibilidad y los recursos simbólicos y discursivos para la construcción narrativa de la identidad" (p. 19), en este punto, no basta con presentar el producto a los usuarios, sino profundizar en el análisis de la interacción continua de estos con el producto y del producto con su entorno.

\section{Conclusiones}

Al ser la primera experiencia COIL de primer nivel de la Carrera de Diseño Gráfico de la PUCE y la segunda de la PUJ Cali en cuanto a este proyecto, se pudo evidenciar la importancia de establecer este tipo de procesos, pues, por un lado, rompe con las barreras físicas para vincularse internacionalmente y por el otro lado facilita la visibilización de la labor del Diseño en diferentes contextos y problemáticas, así como el que los estudiantes puedan relacionar los aprendizajes de las universidades participantes.

Otro aspecto importante es que el proyecto permitió evidenciar que es viable trabajar un proceso real y de contacto con comunidades aun con estudiantes de los primeros niveles de formación en Diseño, además que la metodología es de fácil aplicación tanto a proyectos de gran alcance como a otros más pequeños, generando adaptaciones acordes a cada escenario.

En cuanto a los estudiantes el proyecto permitió la aplicación del conocimiento de cada una de sus materias y el intercambio académico entre pares, además de la capacidad de generar nuevas destrezas de trabajo en equipo y la posibilidad de relacionarse con otras realidades sociales y con procesos fundamentales de diseño que generaron experiencias significativas en su primera fase de formación, además de una aplicación más efectiva de los fundamentos del Diseño que se aprenden en este nivel.

Además, se puede concluir que si bien es cierto la metodología Colores por la vida posee las mismas fases base de otras metodologías de diseño, esta posee tres particularida- 
des importantes: permite estructurar un proceso de trabajo en equipo, se vincula a entornos sociales desde un enfoque inmersivo y en niveles más altos fomenta el trabajo colaborativo con otras disciplinas. Con ello se logró que si bien es cierto los estudiantes no realizaron un proyecto bajo el pedido de un cliente real, si fue un trabajo de campo real, que seguramente les permitirá vincularse con mayor efectividad en los siguientes niveles que ya trabajan con un pedido real.

Finalmente, es importante resaltar la importancia de aplicar estos procesos de aprendizaje basado en proyectos desde los primeros niveles de la Carrera, pues permiten a los estudiantes, aun en niveles básicos, entender la lógica de un proceso gráfico aplicado a situaciones y públicos reales, enfrentando situaciones que solamente se pueden afrontar en la gestión diaria propia del Diseño.

\section{Bibliografía y referencias documentales}

\section{Libros}

Bransford, J. D., BROWN, A. L., y CockING, R.R. (2000). How People Learn: Brain, Mind, Experience, and School: Expanded Edition. Washington: National Academy Press.

JULIER, G., (2010). La cultura del diseño. Barcelona: Gustavo Gili

LEDESMA, M., López, M., Et. Al. (2017). Retóricas del diseño social. Buenos Aires: Wolkowicz.

MANZINI, E., (2015). Cuando todos Diseñan. Una introducción al diseño para la innovación social. Madrid: Gráficas Muriel.

MAZZEO, C., y RomANO, A., (2007). La enseñanza de las disciplinas proyectuales: hacia la construcción de una didáctica para la enseñanza superior. Argentina: Nobuko.

Museo Nacional de Bellas Artes. (S.f.). XIl seminario para docentes de arte Cultura e Imagen. Chile: Dibam.

VIDAL, F., (S.f.) El diseño como construcción de experiencias. España: Universitat Oberta de Catalunya.

\section{Artículos}

ARBOLEDA, F., et al. (2018). Colores para la vida: una experiencia interdisciplinaria de diseño y educación. Educación, aplicación e innovación en diseño, p.119.

DOBERTI, R. (S. f.) Las prácticas sociales dimensiones y niveles. Recuperado de https://www.scribd.com/ document/471423661/Dimensiones-Niveles

MARGOLín, V. (2012). Un "modelo social" de diseño: cuestiones de práctica e investigación. Revista KEPES. Año 9. No.8 Recuperado de: http://vip.ucaldas.edu.co/kepes/downloads/Revista8_4.pdf

MÚNERA, M., y LONDOÑO, C., (S.f.) La investigación social en diseño como una práctica cultural. Revista académica e institucional de la UCPR. https://dialnet.unirioja.es/descarga/articulo/48976g9.pdf

YEDAIDE, M. (2016). Narrativa y enseñanza de lo proyectual: Intermitencias. Trabajo presentado en III Jornadas de Investigadores en Educación de Encuentros de la Facultad de Humanidades / UNMDP. Recuperado de: https:// fh.mdp.edu.ar/encuentros/index.php/jie/3jie/paper/view/1357/714 


\section{Sitios web}

IDEO (s.f.). Design Thinking for Educators. Recuperado de

https://www.ideo.com/post/design-thinking-for-educators

IDEO. (S.f.) Diseño centrado en las personas. Recuperado de: https://hcd-connect-production.s3.amazonaws. com/toolkit/en/spanish_download/ideo_hcd_toolkit_final_combined_lr.pdf

PBKWORKS. (s.f.). What is PBL?. Recuperado de: https://www.pblworks.org/what-is-pbl

WDO (s.f.) World Design Organization. Recuperado de: https://wdo.org/ 